\title{
Oceanic Boundary Conditions for Jakobshavn Glacier. Part I: Variability and Renewal of Ilulissat Icefjord Waters, 2001-14*
}

\author{
CARL V. GLADISH ${ }^{+}$ \\ New York University Abu Dhabi, Abu Dhabi, United Arab Emirates \\ DAVID M. HOLLAND \\ New York University, New York, New York \\ AgQAlu Rosing-Asvid \\ Greenland Institute of Natural Resources, Nuuk, Greenland \\ JANE W. BEHRENS AND JESPER BOJE \\ Technical University of Denmark, Charlottenlund, Denmark
}

(Manuscript received 11 March 2014, in final form 22 October 2014)

\begin{abstract}
Jakobshavn Glacier, west Greenland, has responded to temperature changes in Ilulissat Icefjord, into which it terminates. This study collected hydrographic observations inside Ilulissat Icefjord and from adjacent Disko Bay between 2001 and 2014. The warmest deep Disko Bay waters were blocked by the entrance sill and did not reach Jakobshavn Glacier. In the fjord basin, the summer mean temperature was $2.8^{\circ} \mathrm{C}$ from 2009 to 2013, excluding 2010 , when it was $1^{\circ} \mathrm{C}$ cooler. Despite this variability, summer potential densities in the basin were in the narrow range of $27.20 \leq \sigma_{\theta} \leq 27.31 \mathrm{~kg} \mathrm{~m}^{-3}$, and basin water properties matched those of Disko Bay in this layer each summer. This relation has likely held since at least 1980. Basin waters from 2009 and 2011-13 were therefore similar to those in 1998/99, when Jakobshavn Glacier began to retreat, while basin waters in 2010 were as cool as in the 1980s. The 2010 basin temperature anomaly was advected into Disko Bay, not produced by local atmospheric variability.

This anomaly also shows that Ilulissat Icefjord basin waters were renewed annually or faster. Time series fragments inside the fjord did not capture the 2010 anomaly but show that the basin temperatures varied little subannually, outside of summer. Fjord velocity profiles from summer 2013 implied a basin renewal time scale of about 1 month. In model simulations of the fjord circulation, subglacial discharge from Jakobshavn Glacier could drive renewal of the fjord basin over a single summer, while baroclinic forcing from outside the fjord could not, because of the sill at the mouth.
\end{abstract}

* Supplemental information related to this paper is available at the Journals Online website: http://dx.doi.org/10.1175/JPO-D14-0044.s1.

${ }^{+}$Current affiliation: Department of Earth, Atmospheric and Planetary Sciences, Massachusetts Institute of Technology, Cambridge, Massachusetts.

Corresponding author address: Carl Gladish, MIT Bldg. 54-1423, 77 Massachusetts Ave., Cambridge MA, 02139.

E-mail: carlg@mit.edu

\section{Introduction}

Over time scales of tens to hundreds of millennia, the Greenland Ice Sheet (GrIS) has undergone massive changes in response to changing climate. During the previous interglacial, when boreal summer temperatures were up to $5^{\circ} \mathrm{C}$ warmer than at present, a smaller GrIS contributed $2 \mathrm{~m}$ to a global-mean sea level that was at least $4 \mathrm{~m}$ higher than that of today (Colville et al. 2011; Dahl-Jensen et al. 2013). On multimillenial time scales, 


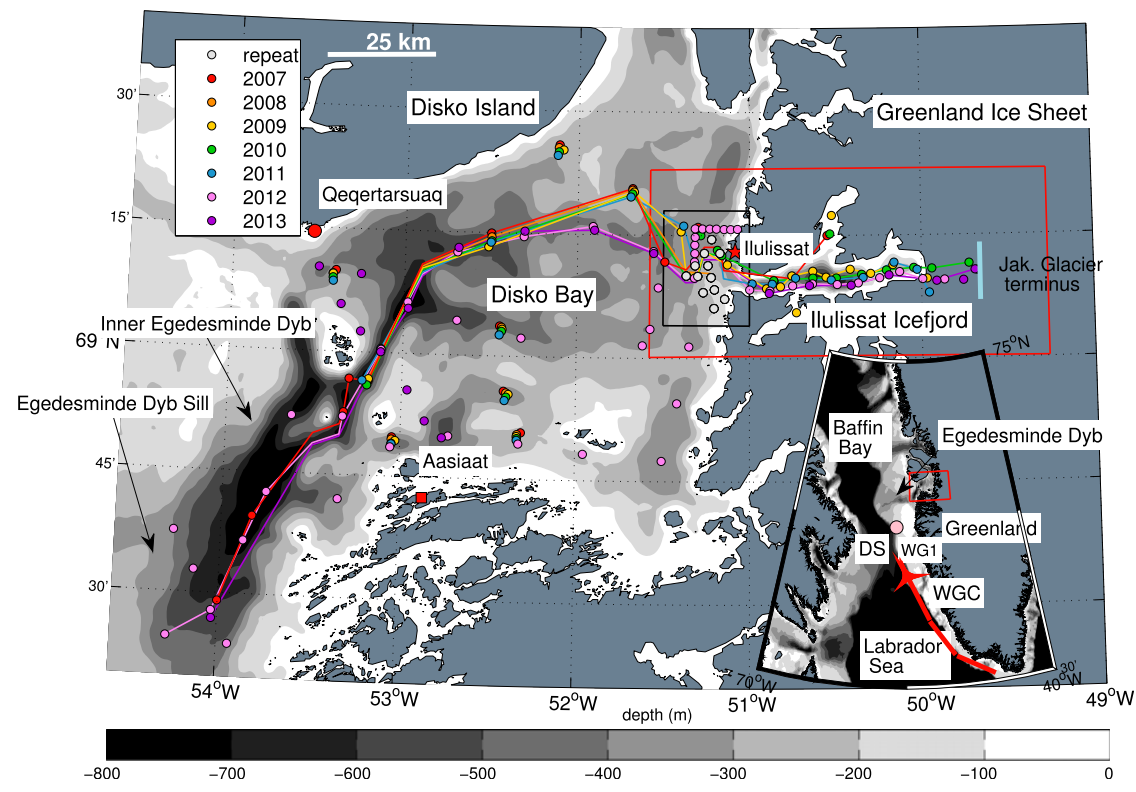

FIG. 1. The main map shows DB and IIf, west Greenland, with bathymetric contours. Markers show the locations for CTD, AXCTD, and XCTD stations from 2007 to 2013. Lines show the interpolation path for vertical sections in Fig. 3. Markers are displaced up to $1 \mathrm{~min}$ of latitude for legibility. The villages of Qeqertarsuaq, Aasiaat, and Ilulissat are marked for reference. The light blue line marks a typical longitude of JG terminus between 2009 and 2011.The black box defines the fjord mouth region (Table 3). The red box shows the extent of the map in Fig. 2. The pink marker in the inset shows the location of mooring WG1 on the east side of DS. The WGC is shown schematically.

large future volume changes of the GrIS will probably be controlled by the feedback between surface elevation and surface temperature (Levermann et al. 2013). In the present era of warming climate, however, in which the GrIS has been contributing to global sea level at a rate of $0.6 \mathrm{~mm} \mathrm{yr}^{-1}$ (Shepherd et al. 2012), ice loss is occurring largely at Greenland's marine outlet glaciers (Rignot and Kanagaratnam 2006; Thomas et al. 2009; Pritchard et al. 2009), which can respond to changing climate, especially ocean temperature changes, through fast dynamical mechanisms (Thomas 2004; Howat et al. 2007).

Jakobshavn Glacier (JG), a marine glacier that terminates into the 750-800-m-deep Ilulissat Icefjord (IIf; $69^{\circ} 10^{\prime} \mathrm{N}, 50^{\circ} 30^{\prime} \mathrm{W}$; see Fig. 1) in west Greenland, has been losing mass more rapidly than other Greenland outlet glaciers in recent years (Howat et al. 2011; Joughin et al. 2008). It appears that its acceleration and retreat were initiated by a switch to warmer ocean temperatures along west Greenland in the late 1990s (Holland et al. 2008; Motyka et al. 2011; Hansen et al. 2012; Rignot et al. 2012). Ocean temperature changes in the adjacent Disko Bay (DB; see Fig. 1) have likely had a controlling influence on JG for at least the past $100 \mathrm{yr}$ (Lloyd et al. 2011). In general, continued observation and further understanding of glacier-ocean interactions around Greenland and Antarctica is necessary for modeling past and future ice sheet changes (Joughin et al. 2012a).
The premise that the surrounding ocean modulates the behavior of JG motivated our collecting a multiyear record of water properties in DB and IIf. These data include annual surveys, moorings, and instrumented seals and Greenland halibut. Similar efforts have been undertaken at several major Greenland outlet glaciers (Rignot et al. 2010; Mortensen et al. 2011; Straneo et al. 2010; Murray et al. 2010; Christoffersen et al. 2011; Rignot and Steffen 2008; Johnson et al. 2011). Summer water properties in DB have been routinely monitored since the mid-twentieth century (Andersen 1981) and more intensively in recent decades (Hansen et al. 2012; Ribergaard 2013). IIf, however, is typically full of icebergs trapped in the deep fjord interior by the 50-245-m-deep sill that runs across the fjord mouth (Schumann et al. 2012), and entering the fjord in a research vessel is typically dangerous or impossible. In section 2, we describe our dataset.

Our main observational result (section 3a) is a record of summer water temperatures in the IIf basin between 2007 and 2013 and an understanding of the relation to Disko Bay waters. The IIf basin, which makes up the major part of the oceanic boundary facing JG, is the $\sim 500$-m-thick layer below the depth of the sill's saddle point $(245 \mathrm{~m})$. Our second main finding (section $3 b$ ), based on disparate fjord time series data, was that the IIf basin had little subseasonal temperature variability. IIf therefore differs from Sermilik Fjord, east Greenland, 
which is dominated by subseasonal variability (Jackson et al. 2014).

We found that the mean summer temperature in the IIf basin from 2009 to 2013 (excluding 2010) was $2.8^{\circ} \mathrm{C}$, which is very similar to the temperature of equally dense DB waters in 1998 and 1999, when JG began to retreat. Fjord basin temperatures in summer 2010 were conspicuously cooler than neighboring years-by about $1^{\circ} \mathrm{C}$. The cooling of the IIf basin (along with equally dense DB waters) from summer 2009 to summer 2010 and the return to 2009-like conditions in summer 2011 raised several questions. First, what effect did the cooler water have on $\mathrm{JG}$, considering that $\mathrm{a} \sim 1^{\circ} \mathrm{C}$ warming in the late 1990 s likely triggered the retreat of the glacier? We address this question briefly in section 4 . Second, what dynamics were responsible for the complete renewal of the fjord basin from one summer to the next? An initial hypothesis might be that the IIf basin is renewed only when denser water appears at the sill depth outside the fjord (Arneborg et al. 2004). We argue in section 5 , however, that the basin is renewed mainly in summer by an overturning circulation driven by subglacial discharge and terminus melting. Subglacial discharge is important in determining melt rates at marine termini in some instances (Motyka et al. 2003; Jenkins 2011; Xu et al. 2013); here, we investigate its role in driving the renewal of IIf. If correct, the renewal mechanisms of IIf and Sermilik Fjord differ. At deepsilled Sermilik Fjord, subglacial discharge has an impact on fjord circulation (Straneo et al. 2011), but the fjord is renewed subseasonally by oscillatory baroclinic currents driven by external wind forcing (Straneo et al. 2010; Jackson et al. 2014). In section 6, we present model simulations of the circulation in an idealized IIf. We used the MITgcm model (Marshall et al. 1997) with a setup similar to that of Xu et al. (2012) and Sciascia et al. (2013), but with an emphasis on how sill geometry affects the efficacy of these two potential drivers of fjord renewal.

Finally, there is the question of the ultimate origin of interannual temperature variability in DB/IIf. In a companion paper (Gladish et al. 2015), we address this question by examining hydrographic and meteorological data from the wider region.

\section{Observational data}

\section{a. Hydrographic profile data}

A profile from the north arm of IIf (Fig. 1) was retrieved using an airborne expendable CTD (AXCTD) probe on 7 August 2007 along with conventional CTD profiles (7 June 2007) at 12 stations selected for annual reoccupation (Fig. 1, gray markers) at the fjord mouth (Holland et al. 2008). On 20 July 2008, profiles at 2 of the 12 standard stations were collected using a Seabird
Electronics (SBE) 19plus V2 CTD. On 3 August 2009, 8 August 2010, 21 July 2011, 28 June 2012, and 19 June 2013, the 12 standard CTD stations were again occupied, along with additional stations some summers. In 2012 and 2013, our CTD surveys covered much of DB (Fig. 1). One SBE 19plus V2 CTD was used in 2009 and another was used for 2010 to 2013. Both instruments were recalibrated between the 2012 and 2013 seasons and showed levels of drift that were small compared to the variability we focus on in this work. After correcting for an assumed uniform drift rate, the accuracy of these CTD data are estimated to be close to factory-determined levels of $\pm 0.005^{\circ} \mathrm{C}$ for temperature and $\pm 0.01 \mathrm{~g} \mathrm{~kg}^{-1}$ for salinity.

Each summer from 2009 to 2013, 9 to 12 expendable CTD (XCTD) probes (Tsurumi Seiki Co.) were successfully deployed from a hovering helicopter into IIf (locations in Fig. 1). Each probe typically sampled the entire water column, transmitting a digital signal along a fine copper wire to a receiver in the helicopter. The accuracy determined by the manufacturer is $\pm 0.02^{\circ} \mathrm{C}$ for temperature and $\pm 0.03 \mathrm{mS} \mathrm{cm}^{-1}$ for conductivity, which corresponds to a salinity accuracy of $\pm 0.05 \mathrm{~g} \mathrm{~kg}^{-1}$. Our XCTD survey of the fjord came within $10-15 \mathrm{~km}$ of the calving front of JG most years and within 1-3 km in 2010 and 2013.

A cross comparison of XCTD and CTD profiles at three standard stations in 2009 showed agreement in temperature to within $0.1^{\circ} \mathrm{C}$ and in salinity to within $0.04 \mathrm{~g} \mathrm{~kg}^{-1}$ below 25-m depth after vertically shifting the XCTD profiles by a few meters (XCTD probes only activate after detecting a minimum conductivity of about $15 \mathrm{mS} \mathrm{cm}^{-1}$ and depths are accurate to within $2 \%$, according to the manufacturer).

Our analysis and interpretation also makes use of hydrographic data collected in DB by researchers of the Arctic Station on Disko Island, described in Hansen et al. (2012). Also, several CTD profiles from DB collected by the Greenland Institute of Natural Resources (GINR) in summer of 2007 were used. Finally, we used a large number of CTD profiles from DB collected annually by the Danish Meteorological Institute (DMI) and the GINR, which can be downloaded from the ICES oceanographic database. ${ }^{1}$

For all profile data, downcast segments were manually selected, avoiding surface and bottom artifacts, and samples were averaged over 2-m vertical bins before subsequent analysis. Salinities and other thermodynamic variables were calculated from conductivity, in situ temperature, and pressure using the International Thermodynamic Equation Of Seawater-2010 (TEOS10) standard ${ }^{2}$ as recommended by IOC et al. (2010) and as implemented by available MATLAB routines (McDougall

\footnotetext{
${ }^{1}$ http://ocean.ices.dk/HydChem/

${ }^{2}$ www.teos-10.org
} 
and Barker 2011). In particular, salinity here refers to Absolute Salinity $S_{\mathrm{A}}$, the mass fraction of dissolved material in a given sample, and is therefore stated with units of grams per kilogram. In these units, $S_{\mathrm{A}}$ differs numerically from salinities $S_{p}$ on the practical salinity scale of 1978 . For waters of the subpolar gyre and Baffin Bay with $S_{p} \approx 34.5$, the relation $S_{\mathrm{A}} \approx\left(S_{p}+0.16\right) \mathrm{g} \mathrm{kg}^{-1}$ may be used for a crude but convenient mental translation.

\section{b. Moorings}

The names, dates, depths, and locations of all moorings are provided in Table 1 . We deployed a mooring carrying a SBE 37 MicroCAT just inside the fjord (Fig. 2, red marker) at 400-m depth in August 2009. Judging by its pressure record, it moved vertically in a series of essentially discrete jumps, suggesting it was displaced by icebergs. It could not have crossed the sill at the fjord mouth before February 2010, although it was eventually recovered $30 \mathrm{~km}$ north of the fjord mouth by a fisherman in June 2010. We therefore split the data for this mooring into four separate segments where the mooring depth was essentially constant (first four series in Table 1). During segments Fjord $400 \mathrm{~m}$ and Fjord $290 \mathrm{~m}$, the mooring must have been east of the sill inside the fjord, and for segments $D B 100 \mathrm{~m}$ and $D B 58 \mathrm{~m}$ the mooring was at shallower depths and had probably somehow moved into DB. Mooring DB $296 \mathrm{~m}$, carrying a Teledyne RD Instruments (RDI) Citadel CTD-NH, was deployed in DB near the fjord mouth (Fig. 2, orange marker) in August 2010 and was shortly after caught by a fisherman. In July 2011, a mooring we deployed near the fjord mouth was again caught by a fisherman less than 3 weeks later. A second mooring, $D B 350 \mathrm{~m}$, was deployed in July 2011 with a newly calibrated SBE 37 west of the fjord mouth, out of range of habitual fishing grounds (Fig. 2, green marker), which we successfully recovered $1 \mathrm{yr}$ later. These moorings all sampled every $10 \mathrm{~min}$. The most extreme $1 \%$ of samples by density were discarded and interpolated over to remove spurious spikes.

For the purpose of comparison, we downloaded data from the Arctic Observing Network archive $^{3}$ from a mooring deployed by University of Washington researchers nearly continuously since 2004 at the Greenland shelf break in eastern Davis Strait (DS). This mooring, identified as WG1, was located at 150-m depth in the path of the West Greenland Current (WGC), which is the primary pathway for warm waters of low-latitude origin to enter Baffin Bay (Fig. 1, inset). At 150-m depth, WG1 was shallower than the warm core of the WGC. It did,

\footnotetext{
${ }^{3}$ www.aoncadis.org
}

TABLE 1. Mooring deployments. Virtual moorings from seal dives sampled irregularly in time and dive locations were scattered as shown in Fig. 2. Precise locations are unknown for Fjord $290 \mathrm{~m}$, DB $100 \mathrm{~m}$, and DB $58 \mathrm{~m}$ because of horizontal motion. The term $\Delta t=$ duration of deployment (days); $T=$ sample period (median time for seal dives; units specified).

\begin{tabular}{lccccc}
\hline \hline & $\begin{array}{c}\text { Lat } \\
\left({ }^{\circ} \mathrm{N}\right)\end{array}$ & $\begin{array}{c}\text { Lon } \\
\left({ }^{\circ} \mathrm{W}\right)\end{array}$ & \multicolumn{1}{c}{ Start } & $\Delta t$ & $T$ \\
\hline Fjord 400 m & 69.1859 & 51.1269 & 4 Aug 2009 & 65 & $10 \mathrm{~m}$ \\
Fjord 290m & - & - & 4 Nov 2009 & 78 & $10 \mathrm{~m}$ \\
DB 100 m & - & - & 10 Feb 2010 & 70 & $10 \mathrm{~m}$ \\
DB 58 m & - & - & 15 May 2010 & 16 & $10 \mathrm{~m}$ \\
DB 296 m & 69.2204 & 51.1869 & 7 Aug 2010 & 14 & $10 \mathrm{~m}$ \\
DB 350 m & 69.1756 & 51.3762 & 25 Jul 2011 & 334 & $10 \mathrm{~m}$ \\
Seals 100m 2013 & - & - & 16 Sep 2012 & 188 & $5.0 \mathrm{~h}$ \\
Seals 300m 2013 & - & - & 18 Sep 2012 & 125 & $7.0 \mathrm{~h}$ \\
Seals 100m 2014 & - & - & 2 Aug 2013 & 268 & $5.5 \mathrm{~h}$ \\
Seals 300m 2014 & - & - & 2 Aug 2013 & 268 & $6.2 \mathrm{~h}$ \\
Seals 500m 2014 & - & - & 10 Sep 2013 & 175 & $10.5 \mathrm{~h}$ \\
WG1 150m 2010 & 67.1054 & 56.3274 & 18 Oct 2009 & 347 & $30 \mathrm{~m}$ \\
WG1 150m 2011 & 67.1057 & 56.3284 & 1 Oct 2010 & 365 & $30 \mathrm{~m}$ \\
\hline
\end{tabular}

however, monitor waters similar in density to IIf basin waters. Two 1-yr-long segments (October 2009-September 2010 and October 2010-September 2011) were extracted, with samples every $30 \mathrm{~min}$ (Table 1 ).

\section{c. Virtual moorings from instrumented seals}

In both September 2012 and August 2013, three ringed seals were captured and instrumented with satellitetelemetered CTD tags provided by the Sea Mammal Research Unit (SMRU) of the University of St. Andrews. ${ }^{4}$ The tags transmitted data from a representative set of depth levels for each seal dive. The longest-lasting tag transmitted dive data for 9 months. The horizontal locations of the seal dives varied over the main fjord and its north and south arms (Fig. 2). The SMRU tags measure temperatures with an accuracy of $\pm 0.005^{\circ} \mathrm{C}$ and conductivities with an accuracy of $\pm 0.01 \mathrm{mS} \mathrm{cm}^{-1}$, which corresponds to a salinity accuracy of about $0.02 \mathrm{~g} \mathrm{~kg}^{-1}$. Using the seal dive profiles, we synthesized five "virtual mooring" time series made up of data extracted at fixed depths in IIf, disregarding the horizontal location within the fjord (Table 1). For instance, Seals $100 \mathrm{~m} 2013$ is made up of data extracted at 100-m depth from dives during the overwinter period 2012/13. The temporal spacing was irregular, so the samples were averaged into 1-day bins and gaps were interpolated over. ${ }^{5}$

\footnotetext{
${ }^{4}$ www.smru.st-and.ac.uk/Instrumentation/SRDL/

${ }^{5}$ Daily samples were missing for $13 \%$ of Seals $100 \mathrm{~m} \mathrm{2013,30 \%}$ of Seals $300 \mathrm{~m} 2013,5 \%$ of Seals $100 \mathrm{~m} 2014,26 \%$ of Seals $300 \mathrm{~m}$ 2014 , and $72 \%$ of Seals $500 \mathrm{~m} 2014$.
} 


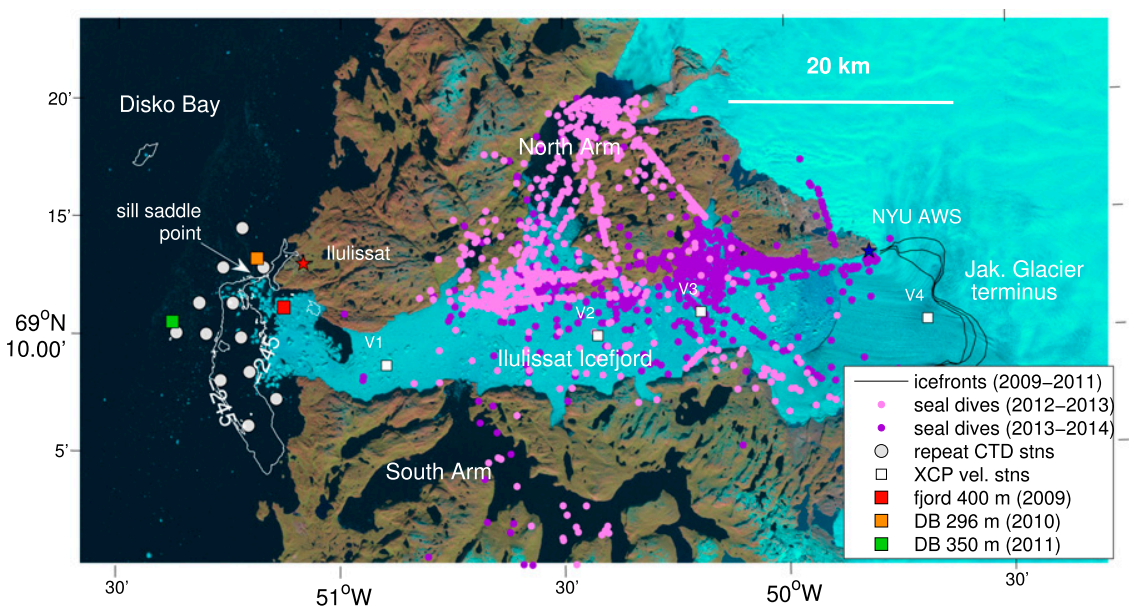

FIG. 2. Background Landsat image (from September 1999) shows iceberg-filled IIf prior to the breakup of the floating proglacial ice shelf of JG. Calving fronts from 2009 to 2011 are shown as black lines. Locations of the New York University (NYU) AWS, mooring sites, XCP velocity stations, repeat CTD stations, and seal dive locations are shown (some appear to be on land because of intermittent position inaccuracies). The $245-\mathrm{m}$ bathymetric contour from Schumann et al. (2012) is shown near the mouth of the fjord. The saddle point at 245-m depth is apparent near the northern side of the fjord mouth.

\section{d. Data from instrumented Greenland halibut}

Between autumn 2001 and autumn 2003, a total of 181 Greenland halibut (a deep-water flatfish) were caught in the waters off Ilulissat (Fig. 1) and tagged with temperature and pressure recording devices. There were 12 fish recovered 50 to 175 days later, either inside IIf or in DB. These data are not precisely geolocated, but by examining the pressure records in relation to the known bathymetry of the region, we identified multimonth time intervals when individuals were very likely inside IIf. Furthermore, of the 12 recaptured fish, 3 were recaptured deep inside the fjord and 3 were just inside the mouth of the fjord, thus confirming their residence inside the fjord. These data therefore provide time series of in situ temperature at 10- to 15-min sampling periods inside the deep basin of the fjord, generally during winter months. Further details on tagging, collection, and processing of these data can be found in Boje et al. (2014).

\section{e. XCP profiles}

Four Lockheed Martin expendable current profilers (XCP) were deployed along the fjord in summer 2013 (locations in Fig. 2). Three of these (V1, V2, and V3) were deployed on 10 June 2013 within 25 min of each other. The fourth (V4) was deployed on 20 June 2013. Velocity measurements were averaged over 5-m vertical bins to reduce random errors. Using temperature profiles recorded by each XCP device and temperatures from nearby XCTD profiles, vertical offset errors were removed (relative to the XCTD depths).

\section{f. Meteorological data}

We used DMI meteorological data from the airports in the towns of Ilulissat and Aasiaat from 2007 to $2012 .^{6}$ An automated weather station (AWS) we maintain near the terminus of JG (Fig. 2) has a nearly complete record of temperature, pressure, and wind velocity from a site $101 \mathrm{~m}$ above sea level since $2007 .^{7}$

\section{g. Bathymetry}

Regional bathymetry, which we extracted from International Bathymetric Chart of the Arctic Ocean version 3 (IBCAO V3) (Jakobsson et al. 2012), plays an important role in determining which water masses are able to reach DB and IIf. One important feature is the Egedesminde Dyb, a 300- to 900-m trough cutting across the continental shelf from the shelf break into DB (Fig. 1, main map and inset). The shallowest part of the trough, southwest of Qeqertarsuaq, is an important barrier for deep water. We refer to this 300-m-deep barrier as the Egedesminde Dyb Sill (EDS). In this paper, we focus our attention to the east of the EDS, while in the companion paper we consider sources of variability to the west of the EDS and the controlling influence of the EDS itself on variability in DB. The second important bathymetric impediment is the Iceberg Bank sill at the mouth of IIf. Swath bathymetry from Schumann et al. (2012) maps this

\footnotetext{
${ }^{6}$ www.dmi.dk/fileadmin/Rapporter/TR/tr13-11.pdf

${ }^{7} \mathrm{http}: / /$ efdl_5.cims.nyu.edu/aws_jig/
} 
seafloor ridge and shows that its deepest point (the saddle point of the sill) is at 245-m depth just southwest of the town of Ilulissat (Fig. 2). Over the southern half of the fjord mouth the sill is no deeper than $150 \mathrm{~m}$. In the following, sill depth refers to the depth of the sill saddle point.

\section{Fjord Variability}

\section{a. Interannual variability from synoptic surveys}

\section{1) Hydrographic SECTIONS OF DB/IIF}

Sections of potential temperature $\theta$, linearly interpolated along the paths shown in Fig. 1 from inner Egedesminde Dyb to nearly JG, are shown in Fig. 3. In the fjord basin, the 500-m-deep bathtub-shaped volume east of Ilulissat, temperatures were quite homogeneous with less than $1.0^{\circ} \mathrm{C}$ of range. Each summer, the densest layers in DB that were able to pass over the sill increased in thickness along the backside of the sill, forming the nearly homogeneous layer filling the fjord basin. In each section, the downward slope of isotherms (and isopycnals, not shown) over the backside of the sill is the signature of a critical flow over the sill and suggests that water was rapidly pouring over the sill into the fjord basin (Whitehead 1998). We therefore refer to the seafloor slope joining the sill to the floor of the fjord basin as the spillway.

When profiles from all years are plotted together on a $\theta-S_{\mathrm{A}}$ diagram (Fig. 4) several things are apparent. First, waters below about 300-m depth in the fjord had properties matching those of waters at intermediate depths (between 100- and 300-m depth) in DB. The densest and warmest waters in DB did not cross the sill (see also Fig. 3). Second, we found that fjord waters in 2009 and 2011-13 were distinctly warmer than in 2007 and 2010. In the warmer years, fjord basin waters were between $2.5^{\circ}$ and $3.0^{\circ} \mathrm{C}$, while in the cooler years they did not exceed $2.0^{\circ} \mathrm{C}$. We define two regions of $\theta-S_{\mathrm{A}}$ space (as shown in Fig. 4 and defined precisely in Table 2), which we refer to as Warm Fjord Water (WFjW) and Cool Fjord Water (CFjW). In Fig. 3, waters falling within the definitions of WFjW and $\mathrm{CFjW}$ are enclosed by black and gray curves, respectively. These curves illustrate the WFjW or CFjW layers extending continuously across DB (centered at 200-m depth or shallower) and into IIf. The exception was 2007, when fjord basin water was between $\mathrm{WFjW}$ and $\mathrm{CFjW}$. Third, we find that, despite nearly $1.0^{\circ} \mathrm{C}$ variations in temperature, fjord basin waters always had potential density anomaly $\sigma_{\theta}$ between 27.20 and $27.31 \mathrm{~kg} \mathrm{~m}^{-3}$. The single AXCTD profile from 2007 had a smaller maximum density partly because of the shallowness of the fjord's north arm.

\section{2) SiLl DEPTH CHARACTERISTICS, 1980-2012}

To determine if IIf basin waters have fallen within this potential density range in the past, we examined CTD profiles collected since 1980 from the standard Arctic Station position southeast of Qeqertarsuaq and from a regularly visited station northwest of Ilulissat. We extracted $\sigma_{\theta}$ at 250-m depth and determined the depth of the $\sigma_{\theta}=27.30 \mathrm{~kg} \mathrm{~m}^{-3}$ isopycnal from these profiles. These are plotted in Figs. 5a and 5b. Except for two outliers, waters at 250-m depth near Ilulissat were in the range $\sigma_{\theta}=27.20$ to $27.33 \mathrm{~kg} \mathrm{~m}^{-3}$ in all summers since 1980 , and the depth of the $\sigma_{\theta}=27.30 \mathrm{~kg} \mathrm{~m}^{-3}$ isopycnal varied between 200 and $350 \mathrm{~m}$. Near Qeqertarsuaq, water densities at $250 \mathrm{~m}$ were slightly higher and the $27.30 \mathrm{~kg} \mathrm{~m}^{-3}$ isopycnals were slightly shallower.

We next divided the data into two groups on either side of the data gap in the mid-1990s, since the interval from 1980 to 1991 had cooler temperatures compared to the interval after 1997. Near Qeqertarsuaq, the $\sigma_{\theta}=$ $27.30 \mathrm{~kg} \mathrm{~m}^{-3}$ isopycnal mean depth descended from 217 to $230 \mathrm{~m}$ from the first time interval to the second, and the potential density anomaly at $250-\mathrm{m}$ depth slightly decreased from 27.332 to $27.326 \mathrm{~kg} \mathrm{~m}^{-3}$. These changes, however, are not statistically significant. At the Ilulissat station, the changes were statistically significant. The mean depth of the $\sigma_{\theta}=27.30 \mathrm{~kg} \mathrm{~m}^{-3}$ isopycnal descended from 249 to $294 \mathrm{~m}$, while the mean $\sigma_{\theta}$ at $250-\mathrm{m}$ depth decreased by $0.06 \mathrm{~kg} \mathrm{~m}^{-3}$ from 27.304 to $27.248 \mathrm{~kg} \mathrm{~m}^{-3}$. Overall, however, it is accurate to say that waters poised to fill the fjord basin have been in the $\sigma_{\theta}=27.2$ to $27.3 \mathrm{~kg} \mathrm{~m}^{-3}$ interval for at least the past three decades. We point out that the downward migration of isopycnals near Ilulissat between the 1980s and 2000s would lead to a slight cooling of waters entering the fjord if the $\theta-S_{\mathrm{A}}$ relationship of DB waters were fixed.

In Fig. 5 c, we plot all of these profiles in $\theta-S_{\mathrm{A}}$ coordinates, along with the definitions of WFjW and CFjW. It is apparent that the cool waters of the 1980s essentially overlap with the $\mathrm{CFjW}$ seen in 2010. Therefore, the range of interannual fjord basin variability from 2009 to 2011 was nearly equal to the full range of variability from the past three decades.

\section{3) DB AND IIF TEMPERATURES, 1980-2013}

In Table 3 and Fig. 6, we present the mean, observed, in situ temperature $T$ of waters inside the fjord, at the fjord mouth, and from DB beyond the fjord mouth area for the years 1980 to 2013 (when available). The earliest known data, from 1879, are also included for comparison (Hammer 1883).

These are subdivided into waters with $\sigma_{\theta}$ typical of the fjord basin $\left(27.20 \leq \sigma_{\theta} \leq 27.31 \mathrm{~kg} \mathrm{~m}^{-3}\right)$ and denser waters. 

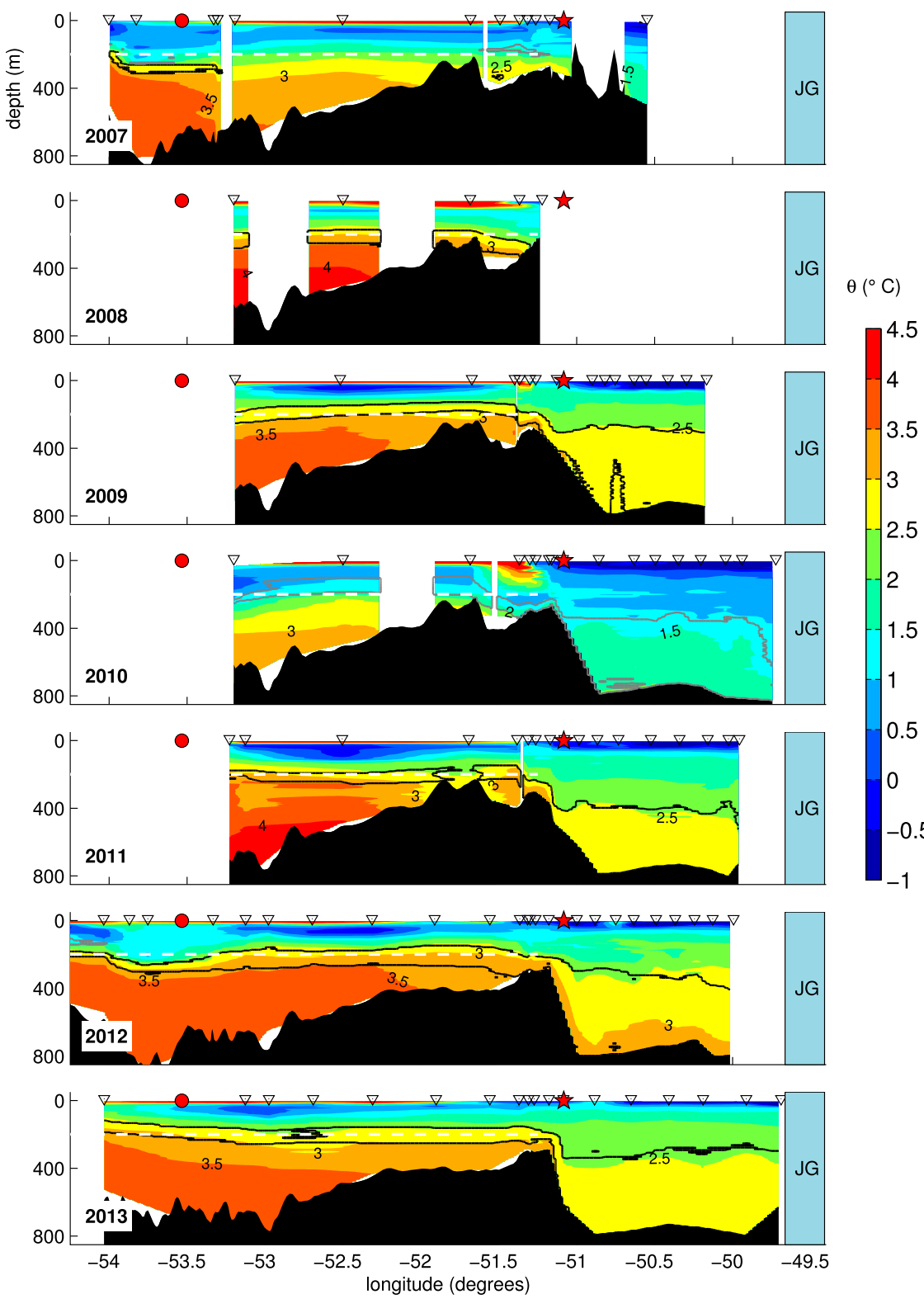

FIG. 3. Sections of summer potential temperature along paths in Fig. 1. Stations are marked by triangles. White space between neighboring profiles indicates the stations were either occupied more than 20 days apart or else were occupied at least 2 days apart and separated by at least $30 \mathrm{~km}$ (i.e., not part of the same synoptic survey). The fjord sill is just west of the red star marking the longitude of Ilulissat. Inner Egedesminde Dyb is just west of the red circle marking the longitude of Qeqertarsuaq. A typical position of the JG terminus is indicated by the blue rectangle. The thin black (gray) contour encloses WFjW $(\mathrm{CFjW})$, as defined in Table 2. The white dashed line indicates 200-m depth. Inside the fjord, bathymetry is from XCTD profiles. Outside the fjord, bathymetry is from IBCAO V3.

Waters of typical fjord basin density at the fjord mouth generally agreed to within $0.20^{\circ} \mathrm{C}$ with $\mathrm{DB}$ temperatures ( $75 \%$ of years) and to within $0.16^{\circ} \mathrm{C}$ with fjord basin temperatures (all but 2010) in that density class. In 2010, the fjord basin was warmer than fjord mouth waters by $0.24^{\circ} \mathrm{C}$, perhaps because of the still ongoing exchange between $\mathrm{DB}$ and IIf. In general, it is reasonable to use the temperature of waters in this density class at the fjord mouth (column 4 of Table 3) as a proxy for the temperature of waters reaching JG.

In Table 3, we identified 15 years as cool $\left(T \leq 1.7^{\circ} \mathrm{C}\right)$ and 7 years as warm $(T \geq 2.7)$ based on the temperature 


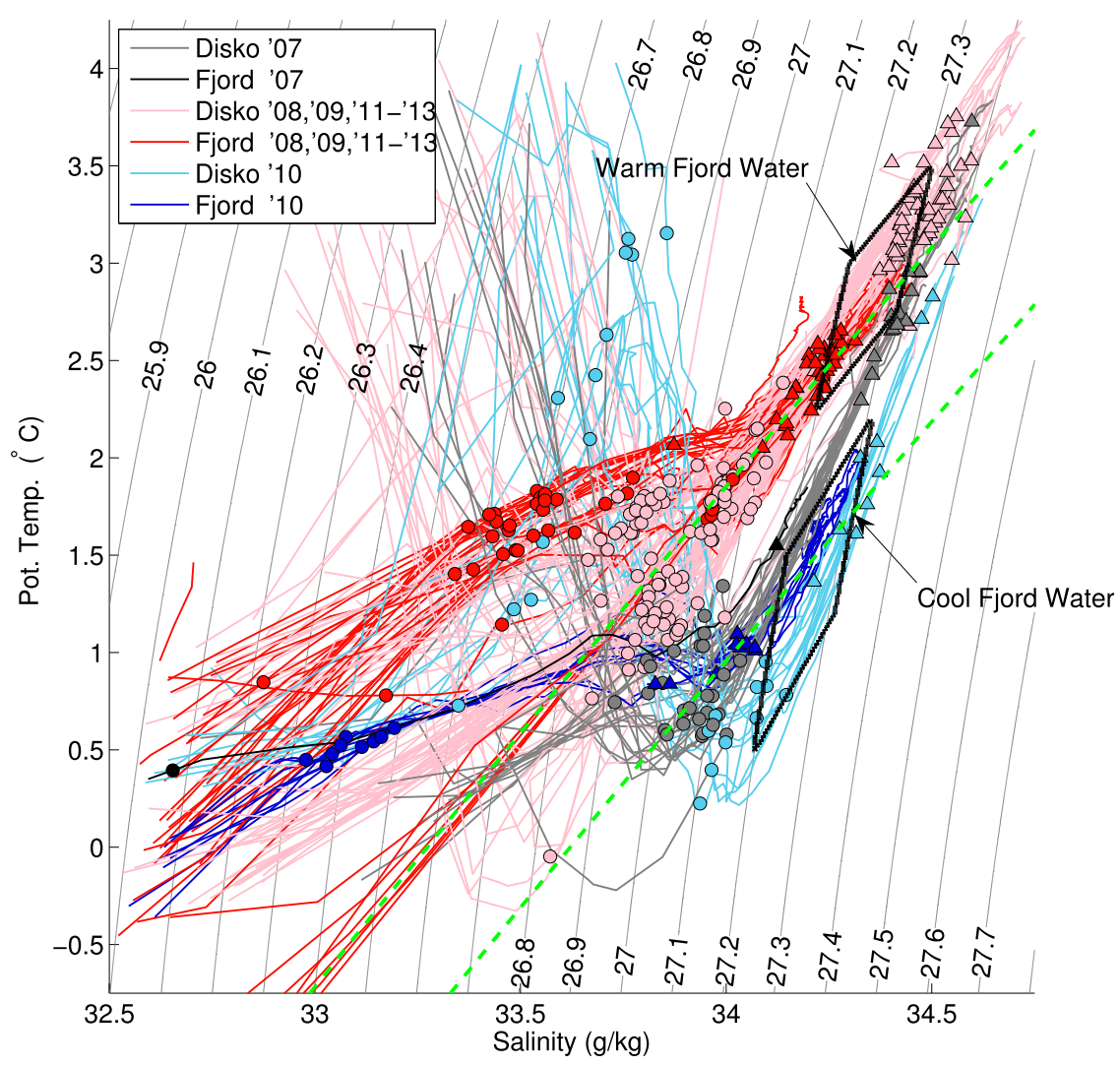

FIG. 4. The $\theta-S_{\mathrm{A}}$ curves for all profiles marked in Fig. 1. The plotting sequence was randomized so that profiles of different colors do not obscure one another in a biased way. Circles (triangles) mark water properties at $100-\mathrm{m}(300 \mathrm{~m})$ depth for each profile. Light colors (pink, light blue, and gray) are profiles from DB, while saturated colors (red, dark blue, and black) are from inside IIf. Background curves are contours of the surface-referenced potential density anomaly $\sigma_{\theta}$. Black contours enclose $\theta-S_{\mathrm{A}}$ regions for $\mathrm{WFjW}$ and CFjW (as defined in Table 2). Dashed green lines are Gade (meltwater mixing) lines.

of waters at the fjord mouth in the $27.20 \leq \sigma_{\theta} \leq$ $27.31 \mathrm{~kg} \mathrm{~m}^{-3}$ range. This categorization captures the persistence of cool conditions until the warming that is apparent in 1997 (Hansen et al. 2012; Holland et al. 2008) and that becomes particularly marked in 1998 and 1999. From 2000 to 2007 water temperatures at the fjord mouth remained warmer than the cool 1980s, but 2001 and 200407 were closer to the cool 1980s than to the extremely warm 1998/99. Summer temperatures from 2008 to 2013 were warmer than ever, except 2010, which was as cool as in the 1980s throughout DB and IIf.

\section{4) Possibility of LOCAL METEOROLOGICAL FORCING}

The 2010 cool anomaly does not appear to be connected with variability of local vertical heat fluxes to the atmosphere. In Fig. 7, we show surface air temperature anomalies from Ilulissat, Aasiaat, and our AWS near JG. These show that the winter and spring preceding the summer of 2010 were actually unusually warm over the
DB/IIf region with high pressure (not shown) and generally low wind speeds (not shown). It might be supposed that warmer surface air temperatures in early 2010 led to reduced sea ice cover that allowed greater heat loss and hence cooling of DB/IIf. However, in late 2010 to early 2011, surface air temperatures were again high, and there was low sea ice cover in Disko $\mathrm{Bay}^{8}$, but this accompanied the rewarming of DB/IIf. We conclude that the 2010 cool anomaly was carried into DB/IIf by ocean currents.

\section{b. Annual and subannual variability}

The summer surveys imply nothing about annual or subannual (periods less than $1 \mathrm{yr}$ ) variability occurring in DB/IIf. Here, we characterize such variability using data from our various moorings, instrumented seals, and Greenland halibut tags.

\footnotetext{
${ }^{8} \mathrm{http}: / /$ nsidc.org/data/seaice_index/index.html
} 
TABLE 2. Water mass definitions.

\begin{tabular}{|c|c|c|}
\hline Water mass & Definition & Comment \\
\hline WFjW & $\begin{array}{l}27.20 \leq \sigma_{\theta} \leq 27.31 \\
\theta \leq \frac{3.25-2.75}{27.31-27.20}\left(\sigma_{\theta}-27.20\right)+2.75 \\
\theta \geq \frac{2.75-2.25}{27.31-27.20}\left(\sigma_{\theta}-27.20\right)+2.25\end{array}$ & $\begin{array}{l}\text { Observed in summers of 2008, 2009, } \\
\text { and 2011-13 }\end{array}$ \\
\hline $\mathrm{CFjW}$ & $\begin{array}{l}27.20 \leq \sigma_{\theta} \leq 27.31 \\
\theta \leq \frac{2.2-1.5}{27.31-27.20}\left(\sigma_{\theta}-27.20\right)+1.5 \\
\theta \geq \frac{1.2-0.5}{27.31-27.20}\left(\sigma_{\theta}-27.20\right)+0.5\end{array}$ & Observed in summer 2010 \\
\hline
\end{tabular}

\section{1) MoOrings AND SEAL Dive DATA}

All mooring and seal dive data are displayed in Fig. 8. Basic statistics for all time series are provided in Table 4. We next present the time series chronologically. Findings illuminating the general character of variability and renewal in the fjord are emphasized.

Over a 65-day interval, temperatures for Fjord $400 \mathrm{~m}$ (located along the spillway; see Fig. 2) varied within a $0.69^{\circ} \mathrm{C}$ range with a mean of $2.89^{\circ} \mathrm{C}$, remaining essentially inside the WFjW category traced out by CTD profiles earlier that summer (2009). Temperature and potential density were well correlated for this mooring, suggesting that temperatures varied mainly as a result of vertical motions of isopycnals outside the fjord, causing layers of varying density to spill over the sill.

After rising to 29-m depth, still inside the fjord but perched $45 \mathrm{~m}$ below the sill depth, Fjord $290 \mathrm{~m}$ encountered a cooler mean $\left(2.60^{\circ} \mathrm{C}\right)$ and a wider range of temperatures $\left(1.57^{\circ} \mathrm{C}\right.$ variation over 78 days) in early winter 2009/10. Water properties varied outside the $\mathrm{WFjW}$ category but remained within the $\theta-S_{\mathrm{A}}$ region traced out by CTD profiles in the previous warm summer. The cool 2010 anomaly definitely did not arrive inside IIf before 21 January 2010.

In early 2010, the mooring (DB $100 \mathrm{~m}$ ) then spent 70 days at 100-m depth in eastern DB or on the sill, we believe. Although cooler, the waters sampled were still not clearly cooler than equally dense waters in the warm summer 2009 CTD survey. The cool 2010 anomaly probably had still not reached eastern DB by 21 April 2010.

By late May 2010, when the mooring (DB $58 \mathrm{~m}$ ) was at just $58-\mathrm{m}$ depth, the mean potential temperature was $1.08^{\circ} \mathrm{C}$. This finally fell within the interval $\left(0.75^{\circ}\right.$ to $\left.1.45^{\circ} \mathrm{C}\right)$ occupied by equally dense waters in the cool CTD survey of August 2010. If the cooling of these near-surface waters was because of the advection rather than winter vertical heat flux, we may tentatively conclude that the unusually cool waters directly observed in the fjord in August 2010 arrived at eastern DB in May of 2010, 2-3 months after unusually cool waters appeared in Davis Strait in March (Fig. 8c).

A single physical mooring recorded these four time series fragments, so they necessarily cover nonoverlapping portions of the year. If we nevertheless compare the power spectra of Fjord $400 \mathrm{~m}$, Fjord $290 \mathrm{~m}$, and DB $100 \mathrm{~m}$ (Fig. 8d), it appears that on subseasonal periods (i.e., up to about 30 days) the variability of these time series are all similar to that of WG1 $150 \mathrm{~m}$ in the path of the WGC. This suggests that subseasonal variability in $\mathrm{DB}$ above the sill depth, perhaps originating in the WGC, is transmitted at least some distance into the fjord by waters leaking over the spillway, even outside of summer.

Mooring DB $296 \mathrm{~m}$ collected just 14 days of data beginning in August 2010. There was $0.6^{\circ} \mathrm{C}$ of warming over the two weeks, but this does not signify the beginning of the return to warm 2011 conditions since the temperature change was associated with lifting isopycnals in $\mathrm{DB}$ rather than warming on fixed isopycnals (Fig. 8a).

The mostly temporally disjoint series DB $350 \mathrm{~m}, W G 1$ $150 \mathrm{~m} 2010$, and $W G 1150 \mathrm{~m} 2011$ were each about $1 \mathrm{yr}$ in duration and sampled from overlapping density ranges. The Disko Bay bottom mooring time series DB $350 \mathrm{~m}$, however, was strikingly less variable than the two WG1 series. The total range of temperature variations for $\mathrm{DB}$ $350 \mathrm{~m}$ was only $0.73^{\circ} \mathrm{C}$, including a background warming trend amounting to $0.37^{\circ} \mathrm{C}$ over the year. This is an order of magnitude less variation than the $4^{\circ}-5^{\circ} \mathrm{C}$ annual range measured by mooring WG1. In fact, at essentially all frequencies WG1 $150 \mathrm{~m}$ showed much greater temperature variability than DB $350 \mathrm{~m}$ (Fig. 8d). Some of the temperature variation at WG1 is associated with the wide range of potential densities (Table 4), but moorings at other depths in eastern Davis Strait show that a large annual cycle of temperature occurs in all WGC isopycnic layers that can connect to deep DB. Gladish et al. (2015) argues that the 300-m-deep Egedesminde Dyb Sill blocks 

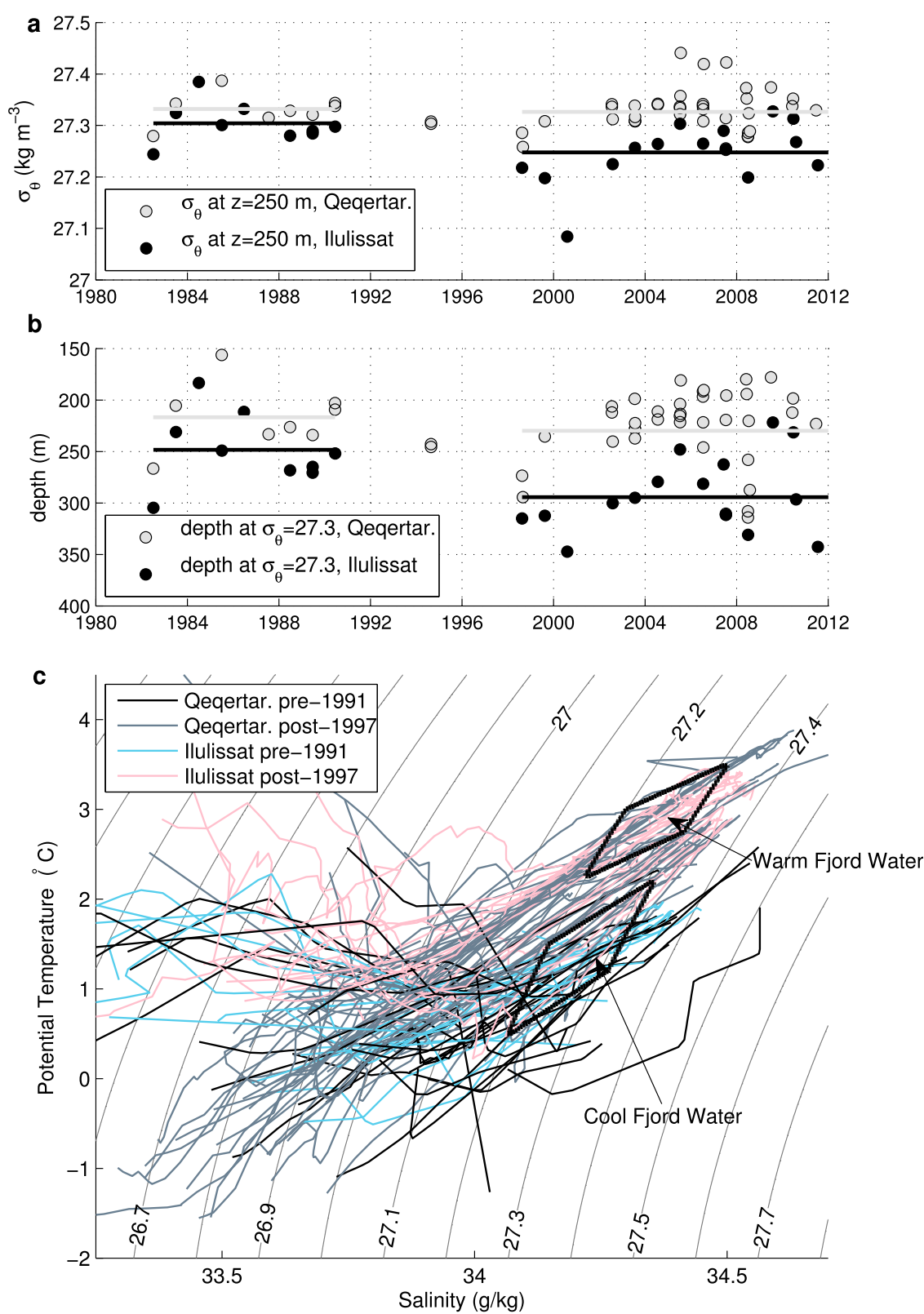

FIG. 5. (a) Potential density anomaly $\sigma_{\theta}$ at 250-m depth from CTD profiles at the standard Arctic Station position near Qeqertarsuaq and near a regular station close to Ilulissat. The mean values for data up to 1991 and for data after 1998 are plotted separately as solid horizontal lines. Only summer [June-August (JJA)] data are shown. (b) Depth of the $\sigma_{\theta}=27.3 \mathrm{~kg} \mathrm{~m}^{-3}$ isopycnal extracted from the same dataset. (c) The $\theta-S_{\mathrm{A}}$ curves for all CTD profiles near the standard Arctic Station position and positions near Ilulissat from 1980 to 2013. WFjW and CFjW $\theta-S_{\mathrm{A}}$ regions are shown.

the warmest WGC waters because those isopycnic layers migrate below the depth of this outer sill during the warm phase of the annual cycle.

Virtual mooring Seals $300 \mathrm{~m} 2013$ shows that IIf temperatures at $300 \mathrm{~m}$ varied over just a $0.36^{\circ} \mathrm{C}$ interval from September 2012 until January 2013. Most of this temperature change was because of the vertical motion of isopycnals in the fjord, which descended until December and then ascended (Figs. 8a,c). From 2-day periods up to 30-day periods, temperature variability at $300 \mathrm{~m}$ in the fjord interior was one-tenth the magnitude of variability in similarly dense waters in the WGC or along the sill spillway (Fig. 8d). Even though subseasonal variability in DB appears to leak over the sill at least onto the 
TABLE 3. Mean in situ temperature for waters in three nonoverlapping geographical areas (fjord interior, fjord mouth, and DB) and two different density categories in summer (JJA). Temperatures from fjord mouth waters in the typical basin density range, the fourth column, make up the basin proxy record. Temperatures at the fjord mouth cooler than or equal to $1.7^{\circ} \mathrm{C}$ are shown in italics and those warmer than or equal to $2.7^{\circ} \mathrm{C}$ are shown in bold.

\begin{tabular}{|c|c|c|c|c|c|c|}
\hline Year & IIf typical $\sigma_{\theta}$ & IIf $\sigma_{\theta}>27.31$ & Fjord mouth typical $\sigma_{\theta}$ & Fjord mouth $\sigma_{\theta}>27.31$ & DB typical $\sigma_{\theta}$ & $\mathrm{DB} \sigma_{\theta}>27.31$ \\
\hline 1879 & - & - & $0.6^{\mathrm{a}}$ & $0.7^{\mathrm{b}}$ & $1.0^{\mathrm{a}}$ & $1.7^{\mathrm{b}}$ \\
\hline 1980 & - & - & 0.40 & 0.38 & 0.74 & 1.21 \\
\hline 1981 & - & - & 0.76 & - & 0.75 & 0.09 \\
\hline 1982 & - & - & 1.46 & 1.75 & 1.54 & 1.78 \\
\hline 1983 & - & - & 1.34 & 1.63 & 1.36 & 1.72 \\
\hline 1984 & - & - & 1.40 & 1.77 & 1.33 & 1.76 \\
\hline 1985 & - & - & 0.94 & 1.29 & 0.93 & 1.60 \\
\hline 1986 & - & - & 1.23 & 1.67 & 1.49 & 1.94 \\
\hline 1987 & - & - & 1.32 & 1.56 & 0.87 & 1.70 \\
\hline 1988 & - & - & 0.96 & 1.28 & 0.95 & 1.52 \\
\hline 1989 & - & - & 1.50 & 1.90 & 1.60 & 2.17 \\
\hline 1990 & - & - & 1.45 & 1.69 & 1.27 & 1.88 \\
\hline 1991-93 & - & - & - & - & - & - \\
\hline 1994 & - & - & 1.08 & 1.32 & 1.13 & 1.52 \\
\hline $1995-96$ & - & - & - & - & - & - \\
\hline 1997 & - & - & 2.23 & - & 2.29 & 3.11 \\
\hline 1998 & - & - & 2.77 & 3.02 & 2.70 & 3.28 \\
\hline 1999 & - & - & 2.79 & 3.26 & 2.74 & 3.44 \\
\hline 2000 & - & - & 2.37 & 2.71 & 2.18 & 3.13 \\
\hline 2001 & $2.01^{\mathrm{c}}$ & - & 2.07 & - & 2.19 & 2.58 \\
\hline 2002 & $2.39^{c}$ & - & 2.60 & 2.89 & 2.66 & 3.11 \\
\hline 2003 & $2.18^{\mathrm{c}}$ & - & 2.47 & 3.11 & 2.41 & 2.97 \\
\hline 2004 & - & - & 1.77 & 2.60 & 1.67 & 2.47 \\
\hline 2005 & - & - & 2.11 & 3.09 & 1.85 & 2.69 \\
\hline 2006 & - & - & 1.61 & 2.49 & 1.68 & 2.59 \\
\hline 2007 & 1.83 & - & 1.97 & 2.81 & 2.18 & 3.14 \\
\hline 2008 & - & - & 2.94 & 3.32 & 3.12 & 3.62 \\
\hline 2009 & 2.85 & 2.95 & 2.77 & 3.28 & 2.70 & 3.41 \\
\hline 2010 & 1.67 & 2.01 & 1.44 & 1.90 & 1.05 & 2.35 \\
\hline 2011 & 2.68 & - & 2.84 & 3.20 & 3.07 & 3.56 \\
\hline 2012 & 2.92 & 3.12 & 3.08 & 3.27 & 2.89 & 3.66 \\
\hline 2013 & 2.64 & - & 2.77 & 3.10 & 2.73 & 3.35 \\
\hline
\end{tabular}

${ }^{\mathrm{a}}$ Mean value between $150-250-\mathrm{m}$ depth.

${ }^{\mathrm{b}}$ Mean value below 250-m depth.

${ }^{\mathrm{c}}$ Mean temperature below 300-m depth, from winter beginning that calendar year.

spillway, these incursions appear to have insufficient volume to affect the fjord basin interior to the east, such that the fjord basin is quiet on subseasonal time scales outside of summer.

Virtual mooring Seals $100 \mathrm{~m} 2013$ shows that, at 100-m depth, fjord waters became denser and warmer from September 2012 until March 2013 as low-salinity waters in the upper layer were replaced by denser and warmer waters more characteristic of surface waters outside the fjord (Figs. 8a,c). At this depth in the fjord, variability is much closer to WGC or shallow DB variability on subseasonal time scales (except for the 7- to 15-day band of periods in 2014, and 15- to 30-day band in 2013, for unknown reasons), indicating that exchange between the external waters and the abovesill layer of IIf probably occurs regularly on subseasonal time scales.
During the next overwinter period from autumn 2013 to spring 2014, variability for Seals $100 \mathrm{~m} 2014$ and Seals $300 \mathrm{~m} 2014$ was similar to the previous year, with basin temperature and density decreasing until December, followed by rising isopycnals and rewarming. Additional spring warming was detected in the longer record from 2014 (compared to 2013) at both 100- and 300-m depths. Sporadic seal dives down to 500-m depth (Seals $500 \mathrm{~m}$ 2014) show that temperatures deeper in the basin were also slowly warming over a $0.63^{\circ} \mathrm{C}$ range from December 2013 to March 2014, with $\sigma_{\theta}$ increasing from 27.06 to $27.18 \mathrm{~kg} \mathrm{~m}^{-3}$ over the same time interval. These changes occurred on a slower-than-seasonal time scale, so the fjord basin can still be described as quiet on subseasonal to seasonal time scales (Fig. 8d). We propose that the lack of subseasonal variability in the fjord basin was because of the weak exchange between DB and the fjord basin 


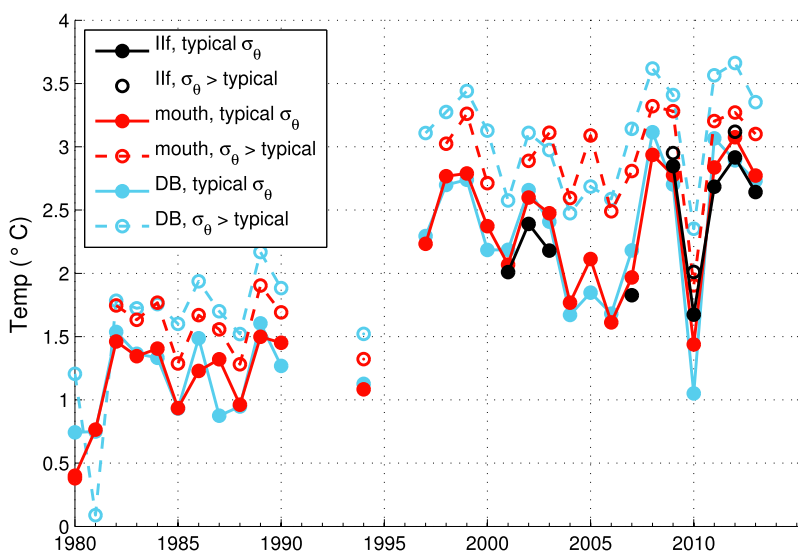

FIG. 6. Temperatures from Table 3. Fjord mouth temperatures in the typical $\sigma_{\theta}$ range make up our basin proxy record.

outside of the summer glacial melt season. IIf basin temperatures still tracked DB temperatures interannually because the basin was renewed each summer.

\section{2) FJORD VARIABILITY FROM INSTRUMENTED GREENLAND HALIBUT, 2001-04}

The instrumented Greenland halibut datasets from 2001 to 2004 do not contain salinity and were therefore not incorporated into the above analysis. In Fig. 9, we show time series of daily averaged temperatures from all measurements below 300-m depth inside IIf. The fish were always initially captured in autumn and recaptured several months later after having swum in IIf most of the winter. The mean temperatures from each overwinter time interval were entered in Table 3 next to DB measurements from the previous summer, since the winter fjord temperatures correlate with fjord mouth temperatures from the series of preceding summers (the winter temperatures being somewhat cooler), but not with the series of following summers. This suggests that the interannual signal is carried into the fjord when the fjord is renewed in summer and is still not overwhelmed by higher-frequency variability several months later. For each overwinter period, the halibut temperature time series ranged over a $<0.4^{\circ} \mathrm{C}$ interval (ignoring 6 outlier days), which is consistent with there being weak subseasonal to seasonal variability in the fjord basin outside of summer.

\section{Relation of fjord variability to JG behavior}

We found that summer-to-summer temperature variations in the IIf basin can be nearly as large (about $1.0^{\circ} \mathrm{C}$ ) as the entire range of temperature variability $\left(1.5^{\circ} \mathrm{C}\right)$ of $\mathrm{DB}$ in the past $100 \mathrm{yr}$, as determined from foraminiferal proxies (Lloyd et al. 2011). Fully investigating the effect of this variability on JG is beyond the scope of this work. Here,
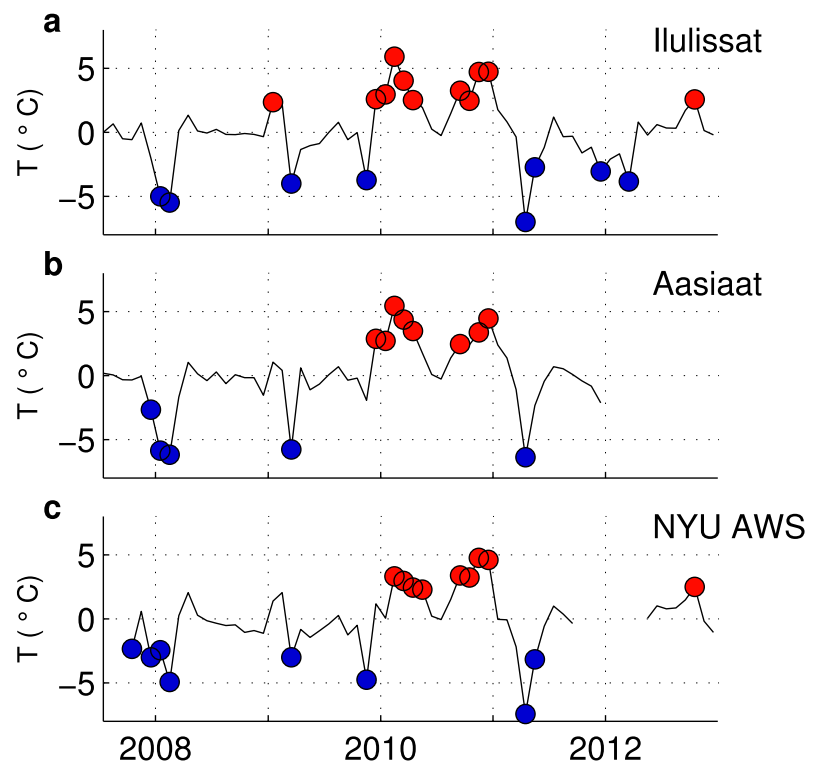

FIG. 7. Monthly-mean surface air temperature anomalies (relative to 2007-12 monthly means) from DMI stations in (a) Ilulissat, (b) Aasiaat, and the (c) NYU automated weather station next to JG (Fig. 2). Anomalies greater (less) than one standard deviation are colored red (blue).

we give only qualitative remarks on the relation between IIf basin temperature variability and the behavior of JG.

As justified above, we refer to the temperature of fjord mouth waters in the $27.20 \leq \sigma_{\theta} \leq 27.31 \mathrm{~kg} \mathrm{~m}^{-3}$ as our basin proxy in years lacking direct measurements in the fjord. On 25 August 1997 the basin proxy was $2.23^{\circ} \mathrm{C}$, the warmest going back to at least 1980 (Table 3). Our basin proxy record is in precise agreement with Motyka et al. (2011), who estimated that a $1.1^{\circ} \mathrm{C}$ warming of the deep fjord water in 1997, relative to the 1980s average, increased melt rates under the then present ice shelf of JG by $25 \%$ and initiated the retreat. Hansen et al. (2012) report even warmer water (above $3.0^{\circ} \mathrm{C}$ ) at $200-\mathrm{m}$ depth in DB near Qeqertarsuaq in summer 1997, but their Fig. 8 shows that the incursion may have been brief, with waters closer to $2^{\circ} \mathrm{C}$ probably filling DB and IIf by the end of the summer. In summer 1998 , the basin proxy reached $2.77^{\circ} \mathrm{C}$. It was in spring of 1998 that the glacier speed underwent a step change increase in velocity along with a significant retreat of the ice shelf (Luckman and Murray 2005).

After 1999, however, glacial variability does not correlate clearly with basin temperature variability. For instance, the near-terminus glacier speed in summer of 2000 was 25\% greater than in 1998 (Luckman and Murray 2005), yet the basin proxy was $0.4^{\circ} \mathrm{C}$ cooler that summer compared to 1998 (Table 3). On the other hand, a slight readvance and deceleration of JG in 2001 (Motyka et al. 2011; Joughin et al. 2008) coincided with further cooling to $2.07^{\circ} \mathrm{C}$. Glacier speeds accelerated from 2000 until 2007 (Joughin et al. 

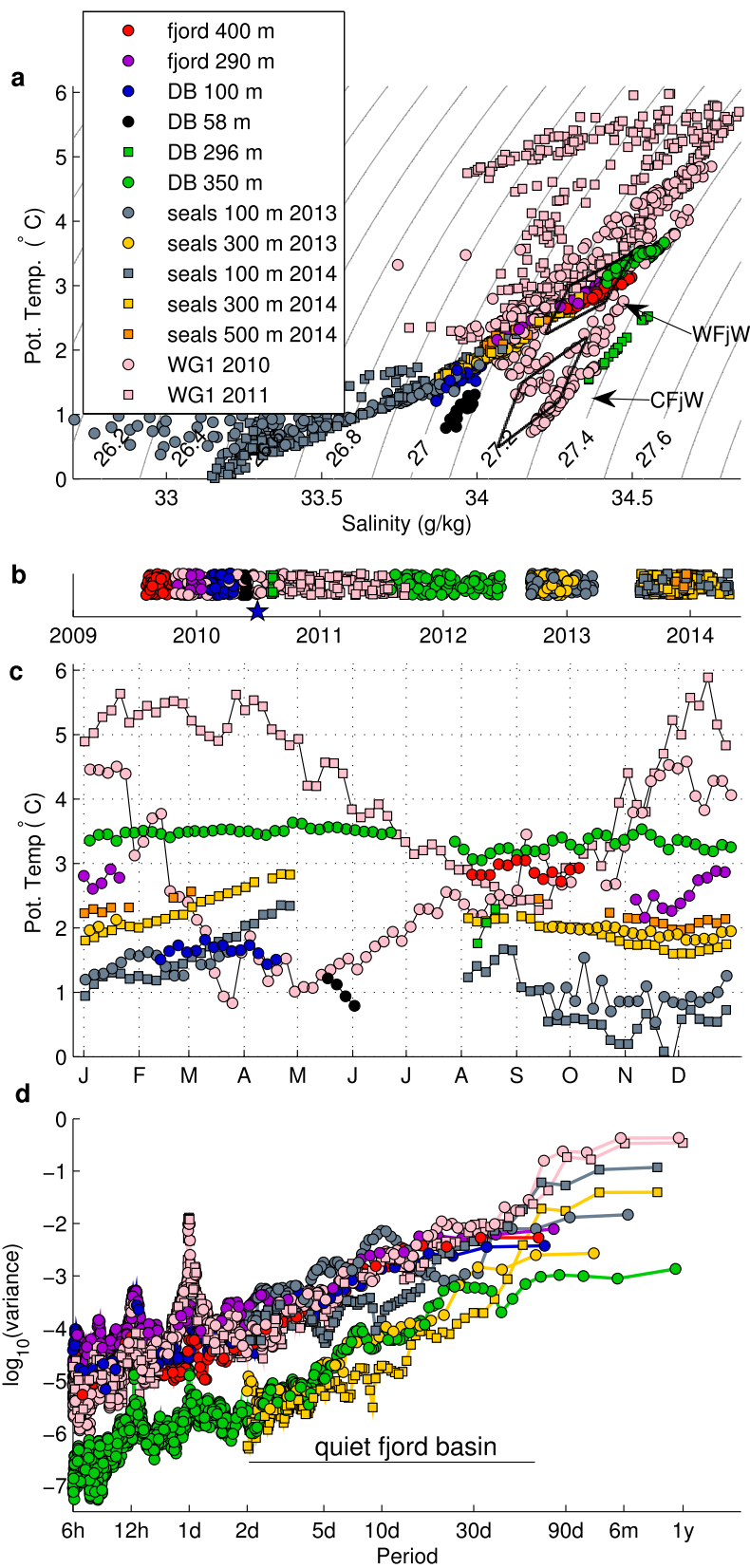

FIG. 8. (a) Daily averaged $\theta-S_{\text {A }}$ properties for moorings deployed in the fjord and in DB as well as virtual moorings assembled from properties extracted at 100- and 300-m depth from instrumented seal dives. Potential density and WFjW/CFjW definitions are shown using black contours. (b) Dates randomly selected from each of these time series are plotted on a timeline. The date of the 2010 summer survey is marked by a blue star. (c) The 5-day-averaged temperature time series for moorings and seal dives. No individual time series were longer than a year, so data are plotted without ambiguity using day-of-year only. (d) Power spectra for the time series longer than 2 months. Pure sinusoids of identical frequency and amplitude, but different duration or sampling frequency would appear here as nearly identical spikes.
TABLE 4. Mooring time series statistics: mean, standard deviation, and total range for potential temperature $\theta\left({ }^{\circ} \mathrm{C}\right)$ and potential density anomaly $\sigma_{\theta}\left(\mathrm{kg} \mathrm{m}^{-3}\right)$. Subtidal refers to the fraction of the variance of $\theta$ in frequencies $f<0.9$ day $^{-1}$.

\begin{tabular}{|c|c|c|c|c|c|c|c|}
\hline & $\bar{\theta}$ & $\begin{array}{l}\text { Std } \\
(\theta)\end{array}$ & $\Delta \theta$ & Subtidal & $\overline{\sigma_{\theta}}$ & $\begin{array}{c}\text { Std } \\
\left(\sigma_{\theta}\right)\end{array}$ & $\Delta \sigma_{\theta}$ \\
\hline Fjord $400 \mathrm{~m}$ & 2.89 & 0.15 & 0.69 & 0.77 & 27.28 & 0.03 & 0.14 \\
\hline Fjord $290 \mathrm{~m}$ & 2.60 & 0.29 & 1.57 & 0.65 & 27.18 & 0.07 & 0.41 \\
\hline DB $100 \mathrm{~m}$ & 1.64 & 0.16 & 1.73 & 0.62 & 27.03 & 0.04 & 0.26 \\
\hline DB $58 \mathrm{~m}$ & 1.07 & 0.22 & 1.63 & 0.18 & 27.07 & 0.05 & 0.31 \\
\hline DB $296 \mathrm{~m}$ & 2.03 & 0.32 & 1.24 & - & 27.40 & 0.02 & 0.10 \\
\hline DB $350 \mathrm{~m}$ & 3.40 & 0.14 & 0.73 & 0.93 & 27.32 & 0.03 & 0.11 \\
\hline Seals $100 \mathrm{~m} 2013$ & 1.06 & 0.48 & 4.22 & - & 26.61 & 0.32 & 1.48 \\
\hline Seals $300 \mathrm{~m} 2013$ & 1.94 & 0.08 & 0.36 & - & 27.09 & 0.02 & 0.14 \\
\hline Seals $100 \mathrm{~m} 2014$ & 0.90 & 0.59 & 3.73 & - & 26.72 & 0.18 & 0.82 \\
\hline Seals $300 \mathrm{~m} 2014$ & 1.92 & 0.27 & 1.31 & - & 27.07 & 0.06 & 0.29 \\
\hline Seals $500 \mathrm{~m} 2014$ & 2.14 & 0.13 & 0.63 & - & 27.09 & 0.03 & 0.13 \\
\hline WG1 $150 \mathrm{~m} 2010$ & 2.67 & 1.23 & 5.12 & 0.93 & 27.24 & 0.12 & 1.20 \\
\hline WG1 150 m 2011 & 4.20 & 1.14 & 4.51 & 0.89 & 27.15 & 0.15 & 1.82 \\
\hline
\end{tabular}

2008), although the proxy record implies that fjord basin temperatures were likely never as warm in those years as they were in 1998 and 1999. The generally high fjord basin temperatures from 2008 to 2013 coincide with a period in which JG continued to retreat and accelerate (Joughin et al. 2012b). We suggest that after 1999 the glacier became less sensitive to basin temperature changes, perhaps because of the loss of its ice shelf or because it was still responding to the sudden perturbation of 1997-99.

The only apparent effect of the cooler waters that arrived in the fjord basin by the summer of 2010 was an apparently more abrupt shutdown in autumn 2010 of the usual enhanced summer glacier velocities and a delayed return of fast flow the following summer (Joughin et al. 2014). As our overwinter halibut data show for prior years, the fjord basin must have remained cool through early 2011. This may have led to reduced undercutting of the terminus, a reduced tendency for calving to occur, and therefore slower glacier flow (Joughin et al. 2008). If the seasonal modulation of calving is controlled by the strength of the proglacial mélange (Amundson et al. 2010), then it seems unlikely that the cool basin temperatures were involved, unless reduced melting of the largest icebergs in the mélange (those that penetrate into the basin) could make the mélange stronger than usual. The possible controlling role of fjord surface waters on the glacier, via influences on the ice mélange, is beyond the scope of this work. The lack of clear correlation between basin waters and glacier behavior since 1999 does suggest looking to surface waters or elsewhere for the main controls on JG behavior in recent years.

\section{Fjord renewal}

Implicit in our discussion of fjord variability and its possible influence on JG is the premise that the temperature 


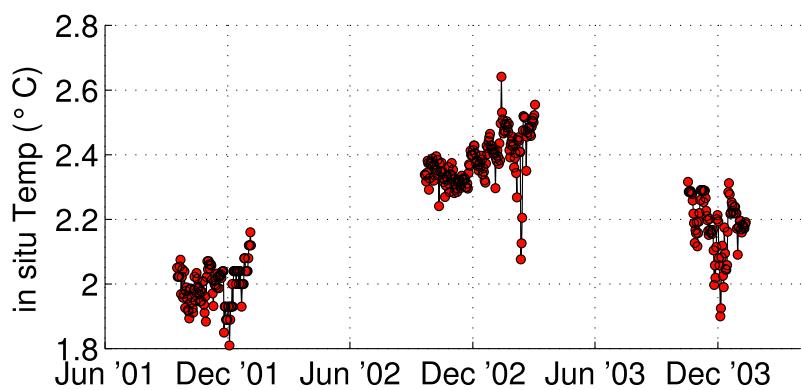

FIG. 9. Daily averaged in situ temperatures below 300-m depth inside IIf from instrumented Greenland halibut.

profile $T_{a}(z)$ of the fjord basin interior is imposed as an ambient boundary condition on the outer edge of a turbulent plume rising next to the glacier terminus. The dynamics of the plume then determine the melt rate (Jenkins 2011; $\mathrm{Xu}$ et al. 2013). In this view, it is understood that the plume temperature $T(z)$ varies, depending on the melt rate and entrainment rate. Yet, it is tempting to assume that $T_{a}$ is determined by external sources only, which is to say that glacier melting does not cool the ambient basin. Indeed, if there were no detrainment of plume water and no recirculation of the plume outflow back down into the basin, then $T_{a}$ would be unaffected by glacier melting. Alternatively, $T_{a}$ might be unaffected by mixing with detrained or outflowing plume waters if the fjord basin were an effectively infinite heat reservoir.

The real basin is not effectively infinite, however, as a simple calculation shows. Suppose the terminus of JG melts at $4 \mathrm{~m} \mathrm{day}^{-1}$, an upper bound for marine glaciers just north of JG (Rignot et al. 2010). Then $1.4 \mathrm{~km}^{3}$ of ice melts because of contact with the lateral face of the $50 \mathrm{~km} \times 8 \mathrm{~km} \times 500 \mathrm{~m}$ basin layer during a 90-day summer. The latent heat required to melt $1.4 \mathrm{~km}^{3}$ of ice is $4.5 \times 10^{17} \mathrm{~J}$. The heat capacity of the $200 \mathrm{~km}^{3}$ basin layer is $8.2 \times 10^{17} \mathrm{~J} \mathrm{~K}^{-1}$. If a dam were installed across the fjord mouth at the beginning of summer, by the end of summer the fjord basin would be $0.5^{\circ} \mathrm{C}$ cooler, which is comparable to the observed interannual variability. By contrast, the $27.20 \leq \sigma_{\theta} \leq 27.31 \mathrm{~kg} \mathrm{~m}^{-3}$ layer in DB has a volume of approximately $100 \mathrm{~km} \times 100 \mathrm{~km} \times 100 \mathrm{~m}=1000 \mathrm{~km}^{3}$, and extracting $4.5 \times 10^{17} \mathrm{~J}$ from this layer would cool it by only $0.1^{\circ} \mathrm{C}$. The DB layer feeding the IIf basin is effectively an infinite heat reservoir for JG, while the IIf basin itself is not.

If the renewal of the IIf basin were rapid (i.e., on average, basin water parcels leave before cycling more than once through the plume), then the ambient basin temperature $T_{a}$ would be close to the fjord mouth proxy temperature. Melting at the terminus would then draw from the inexhaustible heat reservoir of DB, limited only by the heat flux across the plume. If the renewal were slow (i.e., on average, water parcels cycle repeatedly through the plume before being exchanged with DB), $T_{a}$ would become significantly cooler than DB. In fact, the fjord waters are cooler than DB waters at equal depths. Above about 100-m depth, we attribute this to iceberg melting, which modifies the upper fjord water faster than it can be renewed by warmer DB waters (Fig. 4). If basin waters were cooled by interaction with the glacier terminus or deep-drafted icebergs, their $\theta-S_{\text {A }}$ properties would lie along a meltwater mixing line, which they nearly do, below about 300-m depth (Fig. 4). However, DB waters with $\sigma_{\theta} \geq 27.1 \mathrm{~kg} \mathrm{~m}^{-3}$ also lie along the meltwater mixing line. It is also possible, therefore, that the IIf basin contained essentially unmodified DB water at the time of the surveys and that the depressed isopycnals/isotherms simply reflected the sill being a control point for DB waters pouring into the basin. We will argue from a single sparse velocity survey in the fjord that the latter picture is correct, implying that rapid renewal of the IIf basin, in summer, exposes JG to the effectively infinite heat reservoir of DB (and justifying our proposal of the proxy time series).

\section{a. Fjord circulation from XCP data}

\section{1) XCP PROFILES, 2013}

Velocity profiles V1, V2, and V3 (Fig. 2) revealed a baroclinic flow with waters below approximately $300 \mathrm{~m}$ flowing toward the ice at $0.05-0.15 \mathrm{~m} \mathrm{~s}^{-1}$ and water above this flowing seaward (Fig. 10). Profile V4 near the glacier terminus had a somewhat different character, with weak currents down to 600-m depth and a flow of speed $0.15 \mathrm{~m} \mathrm{~s}^{-1}$ toward the terminus of the main trunk of the glacier (i.e., toward the south east) in the deepest $100 \mathrm{~m}$ of the profile.

To interpret these velocity profiles we must consider their degree of contamination by tidal signals. A quantitative analysis in appendix A shows that the barotropic tide was much smaller than the XCP signal at station V1 and was at the level of noise for the other stations to the east. We also show that first baroclinic mode internal tidal velocities in the fjord do not dominate the velocity profiles. We conclude that the XCP profiles contain the signal of a quasi-steady overturning circulation in the fjord.

\section{2) VOLUME/SALT FLUXES AND RENEWAL CIRCULATION}

In Table 5, we record zonal volume and salt fluxes determined from each XCP station. Volume fluxes are vertical integrals of zonal velocity $u$, and salt fluxes are vertical integrals of $S_{\mathrm{A}} \rho u$. Salinity $S_{\mathrm{A}}$ was taken from the nearest XCTD profile, using extrapolation if necessary to cover the depth range for the XCP station. We found 

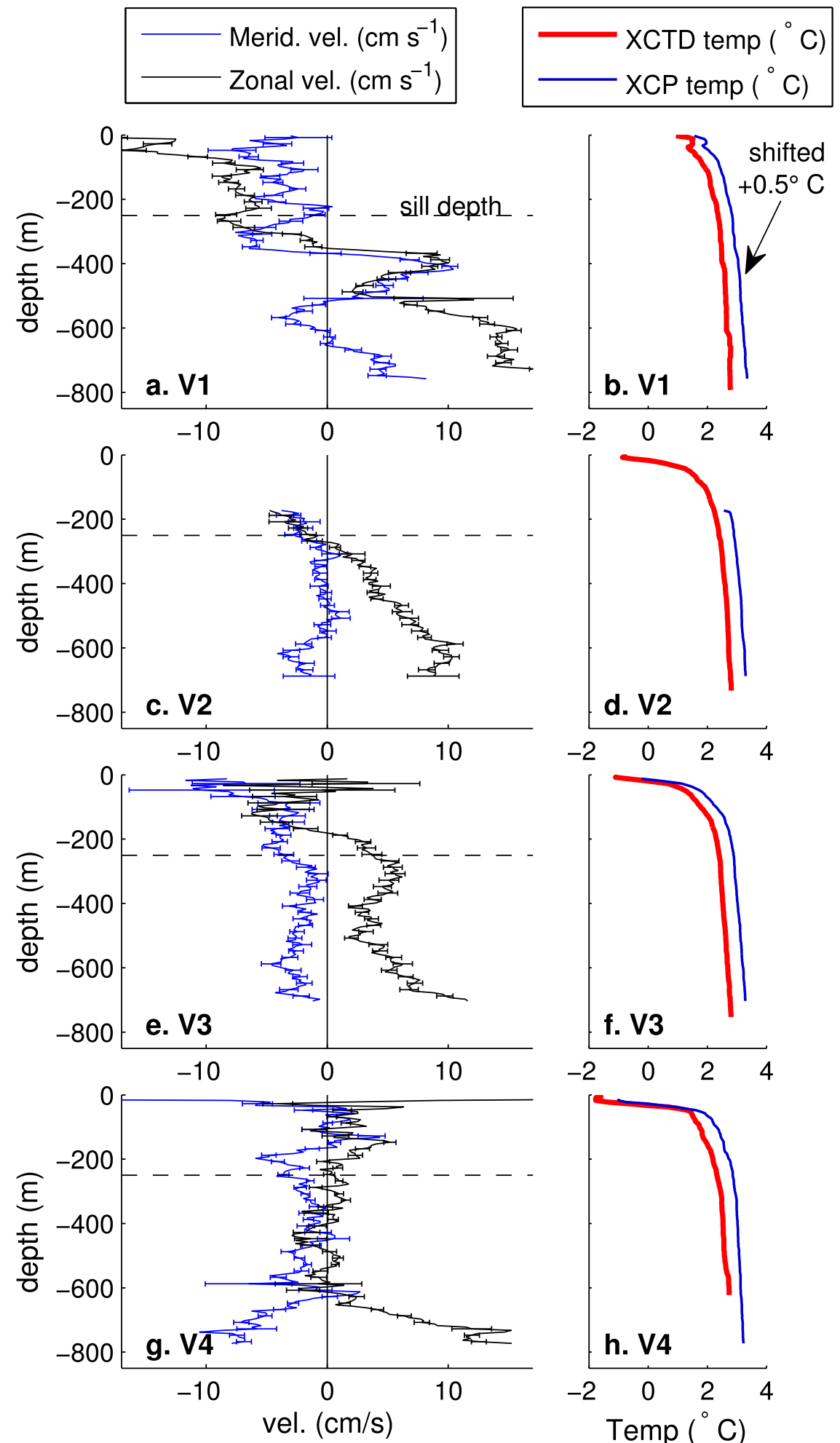

d. V2
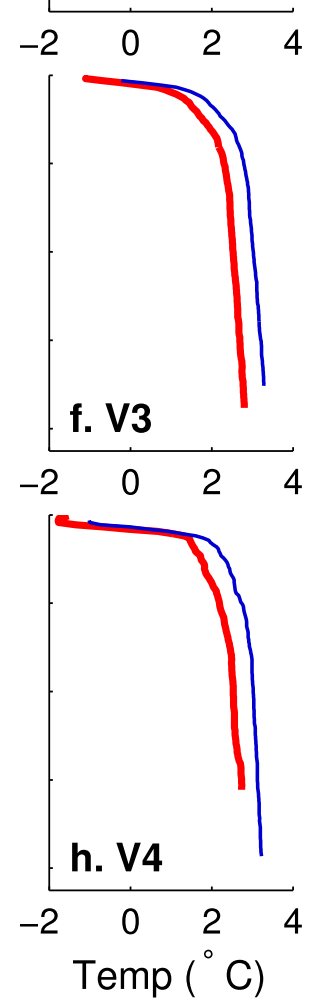

FIG. 10. (a) Profiles of zonal and meridional velocity in summer 2013 at station V1 (Fig. 2). Error bars are estimates for individual samples as determined by the instrument. The fjord sill depth is shown as a dashed line. (b) Temperature profile (red line) from the XCTD station nearest to V1 and temperatures from the XCP probe at station V1 (thin blue line, shown with a $0.5^{\circ} \mathrm{C}$ offset for clarity). (c)-(h) As in (a) and (b), but for stations V2, V3, and V4. 
TABLE 5. Volume and salt fluxes from XCP and XCTD profiles: $z_{0}=$ depth (m) of first measurement; $F_{V}=$ glacierward volume fluxes per unit width $\left(\mathrm{m}^{2} \mathrm{~s}^{-1}\right) ; F_{S}=$ glacierward salt fluxes per unit width $\left(10^{2} \mathrm{~kg} \mathrm{~m}^{-1} \mathrm{~s}^{-1}\right) ; F($ in $)=$ integrated over all depths with positive zonal velocity; $F($ out $)=$ integrated over depths with negative zonal velocity; $F($ net $)=$ integrated over all depths; $F($ deep $)=$ integrated over all depths greater than $250 \mathrm{~m}$; and $S_{\mathrm{A}}(\mathrm{out})=$ salinity required in missing outflow to balance salt flux $\left(\mathrm{g} \mathrm{kg}^{-1}\right)$.

\begin{tabular}{crcccccc}
\hline \hline Station & $z_{0}$ & $F_{V}($ in $)$ & $F_{V}($ out $)$ & $F_{V}($ net $)$ & $F_{V}($ deep $)$ & $F_{S}($ net $)$ & $S_{\mathrm{A}}($ out $)$ \\
\hline V1 & 5 & $43.4 \pm 0.6$ & $-28.3 \pm 0.5$ & $15.2 \pm 0.8$ & $38.7 \pm 0.6$ & $5.5 \pm 0.3$ \\
V2 & 172 & $24.6 \pm 0.3$ & - & - & $24.3 \pm 0.3$ & $-3.3 \pm 2.4$ \\
V3 & 11 & $25.4 \pm 0.8$ & $-5.6 \pm 1.0$ & $19.8 \pm 1.1$ & $22.8 \pm 0.3$ & $7.0 \pm 0.4$ \\
V4 & 13 & $28.5 \pm 1.5$ & $-3.3 \pm 0.4$ & $25.4 \pm 1.5$ & $17.8 \pm 0.5$ & $8.9 \pm 0.8$ & $34.4 \pm 2.8$ \\
\hline
\end{tabular}

an unbalanced volume flux in all the XCP profiles (especially V2, naturally, which omitted the upper water column). If, for instance, the velocity profile at station $\mathrm{V} 3$ was representative of the 8- $\mathrm{km}$ width of the fjord, the net volume flux into the fjord would be $14 \mathrm{~km}^{3} \mathrm{day}^{-1}$. This would double the volume of water in the fjord in less than a month. For comparison, a continuously rising spring tide would double the fjord volume in 6 months. For station V3, the missing outflow could be in the uppermost $11 \mathrm{~m}$ that was not sampled. However, the required speed would be $2 \pm 0.1 \mathrm{~ms}^{-1}$, which seems exceptionally large. At each station there was also a net salt flux into the fjord. We calculated the salinity of the missing outflow needed to eliminate the net salt flux at each station (Table 5), but the error range was too large to confirm that the missing outflow was from the surface. The first inner Rossby radius in the fjord varied from 9 to $12 \mathrm{~km}$ depending on the location and year, which is just slightly larger than the fjord width. It is therefore possible that across-fjord variations account for some of the missing volume outflux (Cushman-Roisin et al. 1994).

Given the lack of closure in the volume fluxes, we could not estimate fluxes of meltwater or runoff into the fjord. However, for stations V2 and V3 the fluxes and zonal velocity toward the glacier were nearly equal below the sill depth. Therefore, we suppose the deep zonal circulation was essentially uniform along the fjord, at least in the central basin. Given that a vertical planar slice along the fjord has area $5 \times 10^{7} \mathrm{~m}^{2}$ and averaging the fluxes at V2 and V3, a volume equivalent to the whole fjord flows past the central fjord basin every $24 \pm$ 0.5 days. If water parcels did not recirculate then this would be the residence time of typical fjord waters. From Fig. 10a it appears that perhaps one-third of the westward-flowing water recirculated below the sill depth. In this case, water parcels spent an average of 36 days in the fjord. We conclude that the fjord basin was on course to be renewed in about 1 month at the time of the XCP survey in June 2013.

\section{b. Discussion of renewal in silled fjords}

For the remainder of this paper, we are concerned with how the fjord circulation glimpsed by the XCP survey could be driven. The challenge is to explain how all the water in the IIf basin, essentially a huge bathtub with no drain, could be exchanged over the sill in less than a year (or, indeed, in as little as 1 month). This requires explanation since basin waters in midlatitude silled fjords are typically renewed episodically only when dense waters appear at the fjord sill to uplift waters in the basin that, meanwhile, have gradually become less dense because of vertical buoyancy fluxes (Inall and Gillibrand 2010; Stigebrandt 2012). When denser water becomes available at the sill, basin renewal in some locations can occur quickly. For instance, at Gullmar Fjord, renewal by inflowing dense water occurs on a time scale of days to weeks (Arneborg et al. 2004). However, the interval between renewal episodes (for instance, in certain Scottish lochs) could be much longer than $1 \mathrm{yr}$ (Gade and Edwards 1980).

Mortensen et al. (2011) studied Godthåbsfjord, south of JG along the coast of Greenland, and described four modes of circulation that can transport heat to the head of the fjord and also bring about fjord-shelf exchange. First is the estuarine mode of circulation present in all fjords in which freshwater runoff enters the fjord at the surface. As this freshwater flows out of the fjord, entrainment along the underside of this layer increases the volume export and hence induces a compensating inflow just beneath. In IIf, there is terrestrial runoff, but any estuarine circulation must occur above the very sharp pycnocline at $100-\mathrm{m}$ depth and is therefore not involved in renewal of the basin. Second is the flow driven by subglacial discharge. At Godthåbsfjord, subglacial discharge is released into the fjord at a relatively shallow depth and an inner sill restricts the depths at which basin waters flow toward the glacier to replenish the water entrained by the subglacially driven plume. At IIf, the fjord basin is essentially flat and this mode, as we will argue, is the main circulation mode. Third, at Godthåbsfjord in winter there are episodic dense water inflow events similar to those observed at Gullmar Fjord that occur once or twice per year, lasting 1 to 3 months. During these events, isopycnals in the fjord rise as existing waters are lifted by the intrusion of denser waters. At IIf, our DB bottom mooring recorded 
no episodes of significantly enhanced density (Fig. 4), and the isopycnals in the fjord (down to $500 \mathrm{~m}$ ) appear to steadily fall until January. Rather than being episodic, the dense inflow into the IIf basin (associated with rising isopycnals) from January until spring appears to be slow and continuous. The fourth mode is termed the intermediary circulation, which is essentially any flow driven by horizontal density gradients at intermediate depths at the fjord mouth. Such gradients may be because of the tilting of existing isopycnals (Klinck et al. 1981; Arneborg 2004) or because of the formation of new density classes at intermediate depths. At Godthåbsfjord, tidally induced mixing creates a warm water mass in summer that is transported into the fjord because of horizontal density gradients.

\section{1) INTERMEDIARY CIRCULATION}

The intermediary circulation mode rapidly flushes some midlatitude fjords (Klinck et al. 1981; Arneborg 2004; Stigebrandt 2012), and it has been shown that alongshore wind variability drives an intermediary circulation that dominates the velocity field of Sermilik Fjord. This circulation causes the waters of that glacial fjord to exchange with external waters on a subseasonal time scale and hence creates large subseasonal variability in the fjord (Straneo et al. 2010; Jackson et al. 2014) We point out, however, that Sermilik Fjord does not have a high sill like IIf. Stigebrandt (2012) states that intermediary circulation does not normally influence basin water.

In a series of two-layer numerical simulations, Klinck et al. (1981) found that intermediary circulation created large deep-layer velocities regardless of the sill height above the seafloor, suggesting that an intermediary circulation could be responsible for renewing the IIf basin. It is physically intuitive, however, that in a sufficiently stratified two-layer system with a sufficiently high sill, deep-layer currents will not be generated on one side of the sill by interface oscillations on the other side of the sill. For instance, the sill could separate the deep layer into disconnected volumes. In appendix B, we show that the indifference of the circulation to tall sills in the model of Klinck et al. (1981) is possibly spurious.

In the seal dive data, there was little subseasonal variability in IIf basin temperatures. A Sermilik-like intermediary circulation is therefore probably absent in the IIf basin (but is probably important above the sill). Also, in our model simulations described below, pycnocline oscillations outside of the mouth of an idealized IIf did not drive renewal of the basin waters on an annual or subannual time scale. The annual or subannual renewal of the IIf basin must be driven by another mechanism.

\section{2) BUOYANCY-FORCED OVERTURNING CIRCULATION}

The glacier terminus at the head of IIf is a buoyancy source because of the melting at the ice face and the discharge of subglacial meltwater. Subglacial discharge can significantly enhance melting at glacier termini (Motyka et al. 2003; Xu et al. 2013; Straneo et al. 2011; Jenkins 2011). Here, we consider the possibility that subglacial discharge also drives the renewal of IIf basin waters.

Unlike during an observed renewal episode at Gullmar Fjord (Arneborg et al. 2004), we never observed a steplike jump in the density profile for nearbottom waters inside the IIf basin. If exchange was actually occurring in 2013 during the XCP/XCTD surveys, then the inflowing waters were not lifting the old basin waters by virtue of having a distinctly larger density as in the Gullmar Fjord renewal episode. Rather, the inflowing waters were at most $0.1 \mathrm{~kg} \mathrm{~m}^{-3}$ denser than overlying basin waters with no sharp interface (Fig. 4). Furthermore, the basin water of 2011 was $0.05 \mathrm{~kg} \mathrm{~m}^{-3}$ less dense than in 2010, which suggests that the waters of 2010 had first to be modified before they were flushed. We propose that, at the time of the $\mathrm{XCP} / \mathrm{XCTD}$ surveys, the plume next to the glacier was entraining massive amounts of basin waters and ejecting the resulting mixture up and out of the fjord.

\section{3) ESTIMATE OF FRESHWATER REQUIRED TO RENEW FJORD BASIN}

To estimate the amount of glacial meltwater required to renew the fjord basin in this way, we make four assumptions: 1) All fjord water below the outflow depth $z_{0}$ must be modified so that its density equals the density $\rho_{0}$ at the outflow depth. 2) This modification is entirely due to mixing with freshwater, not vertical fluxes. 3) The outflow density is not very different from the density of basin waters, so that the ratio of freshwater to seawater is small in the outgoing water. 4) We assume a linear thermodynamic equation of state for seawater. Then, integrating over all water parcels below the outflow depth, the volume $V$ of freshwater required to flush the fjord is

$$
V=\int_{z \leq z_{0}} \frac{\rho(z)-\rho_{0}}{\rho(z)-\rho_{i}} d V
$$

where $\rho_{i}$ is the density of the incoming freshwater.

Analysis of water properties from the 2009 survey indicates that waters at $150-\mathrm{m}$ depth were especially 
influenced by mixing with freshwater (Straneo et al. 2012), so we assume $z_{0}=-150 \mathrm{~m}$. Using a fjord width of $8 \mathrm{~km}$, mean depth of $750 \mathrm{~m}$, and length of $47 \mathrm{~km}$ (from the foot of the spillway to the terminus), the 2009 survey implies $V=4.3 \mathrm{~km}^{3}$ and the 2010 survey implies $V=$ $4.9 \mathrm{~km}^{3}$. The dependence on $z_{0}$ is strong since the outflow density changes rapidly with depth. With $z_{0}=-200 \mathrm{~m}$, only about $1 \mathrm{~km}^{3}$ of freshwater is required. Outflow at $z_{0}=-10 \mathrm{~m}$ would require more than $30 \mathrm{~km}^{3}$.

\section{4) Freshwater Sources IN IIF AND TIME SCALE OF RENEWAL}

Echelmeyer and Harrison (1990) estimated that, over the drainage basin for JG, $650-1350 \mathrm{~m}^{3} \mathrm{~s}^{-1}$ of surface meltwater was produced and entered the glacier upstream of the grounding line from late June to mid-August (observations from July/August 1984-88). Assuming a 90-day melt season, this implies that 5$10 \mathrm{~km}^{3}$ of freshwater potentially crossed the grounding line at JG each summer. More recently, Mernild et al. (2010) used a model constrained by weather station observations and estimated the total amount of glacial runoff from the JG drainage basin to be $1.81-5.21 \mathrm{~km}^{3}$ for 2000-07 (mean of $3.4 \pm 1.1 \mathrm{~km}^{3}$ ), distributed over roughly a 3 -month melt season each year. Given the complete lack of observations of subglacial discharge along the grounding line at JG, we will take $2-10 \mathrm{~km}^{3}$ as a range of possible values.

We next report estimates of the freshwater flux from terminus melting. Jenkins (2011) used a plume model to obtain a summer melt rate of $3.2 \mathrm{~m} \mathrm{day}^{-1}$ near the base of $\mathrm{JG}$, assuming a planar subglacial discharge of $0.17 \mathrm{~m}^{2} \mathrm{~s}^{-1}$ [equivalent to the $1350 \mathrm{~m}^{3} \mathrm{~s}^{-1}$ estimate from Echelmeyer and Harrison (1990) distributed uniformly over a 8-kmlong grounding line]. This estimate assumed a thermal driving of $4.37^{\circ} \mathrm{C}$ based on rather cool temperatures in the north arm of IIf from 2007. From 2009 to 2013 (excluding 2010), the thermal driving at JG below 700-m depth was actually $5.2^{\circ}-5.6^{\circ} \mathrm{C}$. Using observed water column properties from 2009, we determined that the mean melt rate from Jenkins' plume model is $3.9 \mathrm{~m} \mathrm{day}^{-1}$ over the deepest $630 \mathrm{~m}$, using the same subglacial discharge rate. Rignot et al. (2010) estimated mean melt rates ranging from $0.7 \pm 0.02 \mathrm{~m} \mathrm{day}^{-1}$ at Eqip Sermia to $3.9 \pm 0.8 \mathrm{~m} \mathrm{day}^{-1}$ at Sermeq Kujatdleq and Sermeq Avangnardleq in August 2008. At these nearby west Greenland glaciers they were better able to capture the heat, salt, and volume fluxes toward the glacier than we were at IIf because of the heavier ice conditions at IIf. The thermal driving next to Sermeq Kujatdleq/Avangnardleq was $3.8^{\circ} \mathrm{C}$. From these results, a reasonable estimate of the summer melt rate at $\mathrm{JG}$ terminus is $4 \mathrm{~m} \mathrm{day}^{-1}$. Assuming this rate holds over the deepest $600 \mathrm{~m}$ and over a width of
$8 \mathrm{~km}$ for 90 days, an additional $2 \mathrm{~km}^{3}$ of liquid freshwater enters IIf during the summer.

The total amount of liquid freshwater entering IIf at $\mathrm{JG}$ terminus in the summer is therefore $4-12 \mathrm{~km}^{3}$, which is 1 to 3 times the amount required to flush the fjord basin by the freshening mechanism described above $\left(V=4-5 \mathrm{~km}^{3}\right)$. This is consistent with the roughly monthly renewal time scale derived from XCP data.

\section{Model simulations of fjord circulation}

We have provided evidence that the IIf basin is renewed at least once each summer by a circulation driven mainly by subglacial freshwater discharged into the fjord basin. We also suggested that intermediary circulation is probably weak in the IIf basin and not responsible for renewal. To test these hypotheses, we carried out two-dimensional, idealized simulations of the fjord using the MITgcm ocean model (Marshall et al. 1997).

\section{a. MITgcm fjord model setup}

Our model setup was similar to those in $\mathrm{Xu}$ et al. (2012) and Sciascia et al. (2013). New elements in our model setup were our introduction of idealized bathymetry to represent the sill at IIf, our introduction of external baroclinic forcing, longer-duration simulations, and our emphasis on the question of renewal.

\section{1) DOMAIN}

The model domain was designed to capture the gross bathymetric features of DB/IIf, including a 45-km-wide fjord basin, a glacier terminus making up its right vertical boundary, a sill at the mouth, and an open boundary connecting to an idealized DB on the left. In the most realistic model run, there was a 350-m-deep DB, 250-m-deep sill, and an 800-m-deep fjord basin (Fig. 11). In the terminology of Fig. 11, this corresponds to a DB topographic height $H_{\text {Disko }}=450 \mathrm{~m}$ and a sill topographic height $H_{\text {Sill }}=550 \mathrm{~m}$. We also varied $H_{\text {Disko }}$ and $H_{\text {Sill }}$ in some cases to investigate a hypothetical deepsilled geometry.

\section{2) DYNAMiCS}

IIf is narrower than the first Rossby radius so we assumed that cross-fjord gradients are not important for the along-fjord circulation. We therefore configured the model to run in a vertical plane and neglected the Coriolis acceleration. Nonhydrostatic momentum equations were used along with a linearized free surface. The fully nonlinear equation of state for seawater was used. No attempt was made to include the mechanical or thermodynamical influence of icebergs. 


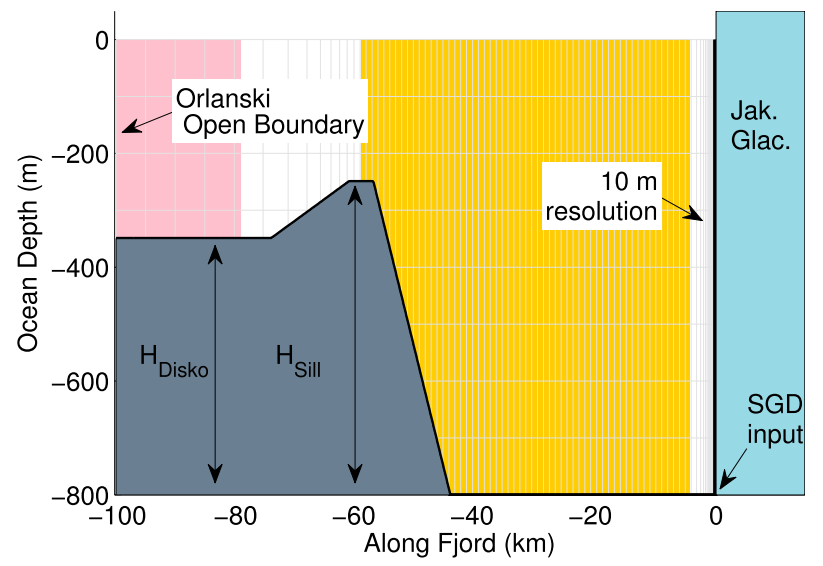

FIG. 11. MITgcm model domain. Pink shading indicates the zone of 500-m horizontal grid size, yellow shading indicates $100-\mathrm{m}$ grid size, and the black stripe is the zone of $10-\mathrm{m}$ grid size. Light gray lines show every tenth grid cell boundary in both directions. The quantities $H_{\text {Sill }}$ and $H_{\text {Disko }}$ from Table 6 are defined here.

\section{3) DiscretiZAtion}

The model used eighty 10-m vertical levels. The need to resolve vertical gradients at all depths (including over the sill) and our omission of surface forcing led to our choice of uniform vertical resolution. Horizontal grid size varied gradually from $500 \mathrm{~m}$ outside the fjord to $100 \mathrm{~m}$ inside the fjord to $10 \mathrm{~m}$ in the final $500 \mathrm{~m}$ next to the model glacier (Fig. 11). Our finest grid spacing is identical to the near-glacier grid size of Sciascia et al. (2013). The nominal width of our grid in the third (unmodelled) dimension was $1 \mathrm{~m}$.

\section{4) SUBgRID PARAMETERIZATION}

The horizontal eddy viscosity and diffusivity were set to $0.25 \mathrm{~m}^{2} \mathrm{~s}^{-1}$, in accordance with the discussion in Sciascia et al. (2013) in the context of Sermilik Fjord. Vertical mixing made use of the KPP scheme (Large et al. 1994) with conventional parameters and background vertical diffusivities and viscosity of $1 \times 10^{-4} \mathrm{~m}^{2} \mathrm{~s}^{-1}$.

\section{5) TIME}

The time step for all runs with subglacial discharge was $2 \mathrm{~s}$, while other cases used a 5-s time step. This choice was constrained by the high vertical velocities of the plume (exceeding $1 \mathrm{~m} \mathrm{~s}^{-1}$ ) in cases with subglacial discharge. The model fluid was initially at rest and all water columns were initialized using a summer 2009 CTD profile from near the mouth of IIf. Outside the sill, the CTD profile was extended in depth as necessary by repeating the deepest observation. Inside the basin the initial temperature and salinity were set equal to the values at the sill depth. All cases were run for 100 days.

\section{6) BOUNDARY CONDITIONS}

We applied no surface wind stress or surface fluxes of heat or freshwater. Sea ice was not included. Along the left boundary, which represents the connection to far-field Disko Bay, Orlanski open boundary conditions (Orlanski 1976) were applied in the momentum equations, which allowed fluid to leave the domain. Temperature and salinity were prescribed on the left boundary using the same summer 2009 CTD profile used to initialize the model. Along solid boundaries, friction was parameterized using a quadratic drag law with nondimensional drag coefficient $C_{D}=2.5 \times 10^{-3}$.

\section{7) PASSIVE TRACERS}

At the beginning of each run two passive tracers were initialized. Both tracers were initially zero left (outside) of the fjord mouth. Inside the fjord, the basin tracer was initially equal to 1 below the sill depth and 0 above, while the above-sill tracer was initially equal to 1 above the sill depth and 0 below. The tracers were allowed in principle to leave the domain because of the Orlanski open boundary, while tracer values on the boundary were set to zero so that any fluid entering the domain was tracer free. The purpose of the tracers was to determine the fraction of fjord water exchanged in response to different forcing and bathymetry.

\section{8) FORCING MECHANISMS}

The right boundary of the domain was a vertical wall representing the glacier terminus. In some model runs, ice-ocean thermodynamical interactions (i.e., melting) were activated along this wall using the MITgcm module described in $\mathrm{Xu}$ et al. (2012). In certain runs, subglacial discharge was added by injecting freshwater into the deepest and rightmost fluid cell in the domain (Fig. 11). Unlike Xu et al. (2012) or Sciascia et al. (2013), we did not account for the shape or distribution of subglacial channels but rather assumed that discharge is uniform along the grounding line. Subglacial discharge added to the model was assumed to enter the domain with no kinetic energy and with temperature and salinity of zero. The true amount of summer subglacial discharge into IIf is highly uncertain. Given the $2-10 \mathrm{~km}^{3}$ range of estimates described above, we took $5 \mathrm{~km}^{3}$ as a central estimate and $10 \mathrm{~km}^{3}$ as an upper estimate. Assuming summer subglacial discharge is distributed uniformly along the grounding line of JG (of nominal width $L=8 \mathrm{~km}$ ) over a 90-day period, we therefore used a planar subglacial discharge rate $F=0.08 \mathrm{~m}^{2} \mathrm{~s}^{-1}$ or $F=0.16 \mathrm{~m}^{2} \mathrm{~s}^{-1}$ in our two-dimensional model. In the model, the area flux $F$ was truly added to the deepest and rightmost $10 \mathrm{~m} \times 10 \mathrm{~m}$ model cell, such that the net flux out of this square was $F$. 
An area flux $F$ was therefore also removed evenly along the open (left) boundary.

To induce an intermediary circulation, we forced the pycnocline to oscillate at the left boundary in some model runs. In these cases, we altered the boundary values of temperature and salinity to vertically shift the interface between the cool and low-salinity Polar Water (PW) layer and the warmer and more saline Atlantic Water (AW) layer (Fig. 12). Over a period of 10 days, the interface was shifted downward by $200 \mathrm{~m}$ and brought back to its original position. Forced pycnocline oscillations were meant to induce an intermediary circulation as observed in Sermilik Fjord. Our 10-day period is at the upper end of periods observed there (Straneo et al. 2010; Jackson et al. 2014). The 200-m amplitude is extreme, but, because of interaction with the Orlanski boundary condition, was necessary to induce the pycnocline to oscillate a more reasonable $50 \mathrm{~m}$ a few kilometers east of the open boundary. The observations necessary to determine whether similar baroclinic forcing exists outside IIf have not been made. Here, we investigated what role such forcing could play in renewing IIf, if it exists.

\section{b. Model runs}

Table 6 describes our set of model runs. Control experiments (labeled C) were run without subglacial discharge or pycnocline oscillations, but with melting activated. Cases with subglacial discharge used either the equivalent of $5 \mathrm{~km}^{3}$ (S5) or $10 \mathrm{~km}^{3}$ (S10) total summer discharge. Cases with forced pycnocline oscillations are denoted $\mathrm{P}$. The shape of the bathymetry was varied as well. The designation $\mathrm{H}$ indicates a high sill, similar to the real IIf sill, while L indicates a low sill, submerged deep in the lower layer like at Sermilik Fjord. A final $\mathrm{m}$ indicates that a case had glacier melting activated. Otherwise, the glacier wall was treated as a regular solid boundary, though possibly with subglacial discharge. By running without melting we could determine if the additional buoyancy supplied by melting was important compared to that from subglacial discharge.

\section{c. Model results}

\section{1) SNAPSHOTS OF KEY RUNS}

Snapshots from five model runs are shown in Fig. 13. Model outputs are from day 50 or from the first episode of peak surface layer inflow following day 50 in the forced pycnocline runs. Contours of the instantaneous streamfunction $\psi$ are shown for each case, where $\psi=0$ by definition along the fjord basin bottom and glacier terminus wall. Throughout the domain, the horizontal velocity $u$ and vertical velocity $w$ are given by $(u, w)=(-\partial \psi / \partial z, \partial \psi / \partial x)$,

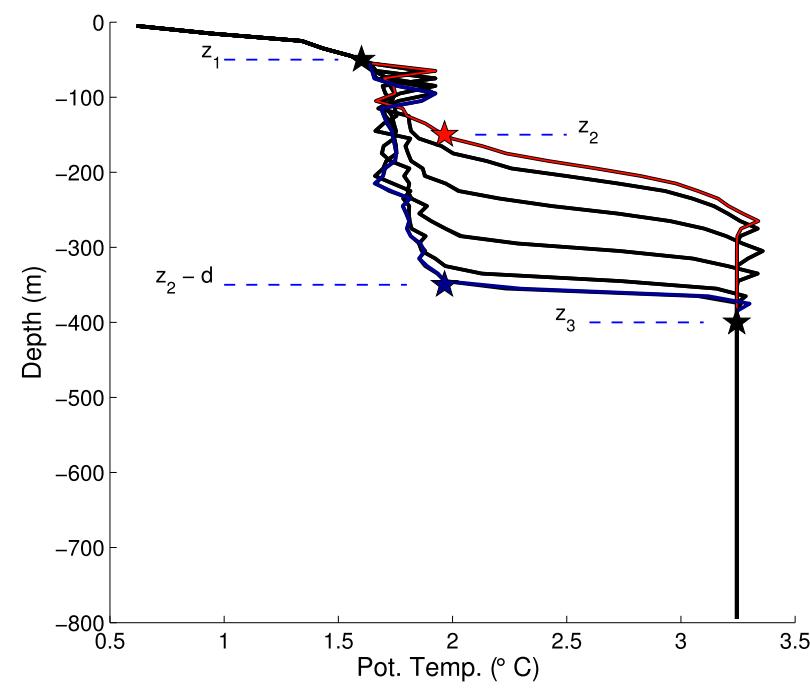

FIG. 12. Pycnocline oscillations designed to induce an intermediary circulation. Shown here are the prescribed temperature profiles during the descent of the pycnocline for cases $P_{-} L / P \_L m$. Points above $z_{1}=-50 \mathrm{~m}$ and below $z_{3}=-300 \mathrm{~m}$ were fixed. The point at $z_{2}=-150 \mathrm{~m}$ (red star) was moved down to $z_{2}-d=-350 \mathrm{~m}$ (blue star) and then back up to $z_{2}$ over the 10-day period, varying sinusoidally in time. Segments joining $z_{2}$ to $z_{1}$ and $z_{3}$ were vertically stretched or compressed to maintain continuity.

so the difference in $\psi$ yields the area flux $\left(\mathrm{m}^{2} \mathrm{~s}^{-1}\right)$ between any two streamlines.

In case C_Hm (Fig. 13a), melting was permitted, but there was no subglacial discharge or external baroclinic forcing to initiate motion near the glacier wall. Mathematically, no buoyant plume will develop in an initial state of rest that is horizontally homogeneous, since the melt parameterization does not represent the molecular heat transfer that would initiate convection in this situation (Xu et al. 2012). In case C_Hm, however, an upwelling meltwater plume did develop next to the glacier within the first 6 model hours in response to a tiny minimum value imposed on the rate of heat transfer into the ice. ${ }^{9}$ The meltwater plume eventually reached a maximum vertical speed of $7 \mathrm{~cm} \mathrm{~s}^{-1}$ and a maximum vertical area flux of $2.5 \mathrm{~m}^{2} \mathrm{~s}^{-1}$ but did not rise above the sill depth. Most of the plume outflow recirculated back into the fjord basin.

In case S5_Hm (Fig. 13b), which had a realistic sill, active glacier melting, and realistic subglacial discharge, there was a vigorous overturning circulation in the fjord that caused rapid exchange with DB. As in the observations, the warmest $\mathrm{DB}$ waters did not enter the IIf basin and isopycnals sloped downward slightly over the

\footnotetext{
${ }^{9}$ Without the imposed minimum, an identical plume still developed after 20 model hours, initiated simply by nonzero velocities associated with roundoff errors from the discretization.
} 
TABLE 6. MITgcm model run definitions.

\begin{tabular}{|c|c|c|c|c|c|}
\hline Case & Melting & $\begin{array}{l}\text { SGD } \\
\left(\mathrm{km}^{3}\right)\end{array}$ & $\begin{array}{l}\text { Pycnocline } \\
\text { oscillations }\end{array}$ & $H_{\text {Disko }}(\mathrm{m})$ & $H_{\text {Sill }}(\mathrm{m})$ \\
\hline C_Hm & $\nu$ & 0 & - & 450 & 550 \\
\hline C_Lm & $\nu$ & 0 & - & 0 & 100 \\
\hline S5_Hm & $\nu$ & 5 & - & 450 & 550 \\
\hline S5_H & - & 5 & - & 450 & 550 \\
\hline S5_Lm & & 5 & - & 0 & 100 \\
\hline S10_Hm & $\nu$ & 10 & - & 450 & 550 \\
\hline P_Hm & v & 0 & $\nu$ & 450 & 550 \\
\hline P_H & - & 0 & $\nu$ & 450 & 550 \\
\hline P_Lm & & 0 & $\nu$ & 0 & 100 \\
\hline P_L & - & 0 & $\nu$ & 0 & 100 \\
\hline
\end{tabular}

sill spillway. The fact that the surface layer in the model was thinner and warmer than in reality must be due, at least partly, to the absence of icebergs in the model. The most extreme streamfunction value near the glacier was $\psi=-22.5 \mathrm{~m}^{2} \mathrm{~s}^{-1}$ (see magnified view of S5_Hm in Fig. 14), implying that the initial subglacial discharge flux of $0.08 \mathrm{~m}^{2} \mathrm{~s}^{-1}$ had been amplified by a factor of 280 in the upwelling plumelike boundary layer. The maximum vertical velocity in the plume was $1.04 \mathrm{~m} \mathrm{~s}^{-1}$ at $240-\mathrm{m}$ depth. Below 170-m depth and above the sill, $15.6 \mathrm{~m}^{2} \mathrm{~s}^{-1}$ flowed into the fjord over the sill, with a compensating outflow above this. This inflow renewed most of the fjord (except for a shallow stagnant layer near the surface), which had an area of $4.3 \times 10^{7} \mathrm{~m}^{2}$ in the model. At this rate of flux, all the basin water would have left the fjord after 32 days ( 28 days if we remove the upper $100 \mathrm{~m}$ ), which is in agreement with the renewal time-scale estimate from the XCP profiles. In the interior of the basin, $\psi$ attained values of -24 to $-48 \mathrm{~m}^{2} \mathrm{~s}^{-1}$ on contours that were closed inside the basin. These streamlines did not pass through the plume but were associated rather with a slower whole basin overturning current. This overturning was a product of the model having not yet reached equilibrium with the external water column. During this adjustment period, basin waters had an artificially long residence time (because they were slightly too dense) and turned over and over in the basin until they had cooled and freshened enough to leave the basin.

In case P_H (Fig. 13c), with no glacier melting or subglacial discharge, pycnocline forcing at the left boundary induced a transient circulation that was most energetic above the sill depth. A flux of $9.9 \mathrm{~m}^{2} \mathrm{~s}^{-1}$ was flowing out over the sill at the time of this snapshot, with an equal flux into the fjord surface layer above. Given that the area of the model fjord above the sill depth was $1.5 \times 10^{7} \mathrm{~m}^{2}$, this flux would renew the upper fjord layer in 17.5 days if it were sustained. Since the flow was actually oscillatory, much of the fjord surface water that left during one-half of the cycle flowed back into the fjord during the next half, making the renewal inefficient, in the sense of Arneborg (2004). Gradually, renewal of the upper layer did occur, however, while the basin waters exhibited seiche-like motions but remain trapped in the basin (see tracer animations in the supplemental information).

In case P_Hm (Fig. 13d), melting was activated and the result was roughly the sum of cases $\mathrm{C}_{-} \mathrm{Hm}$ and $\mathrm{P} \_\mathrm{H}$. The meltwater plume had little effect on the circulation above sill depth (a $\psi=0$ contour cut off the basin from the overlying waters in this snapshot), but caused overturning in the basin. Case $\mathrm{P}_{-} \mathrm{Hm}$ is perhaps similar to IIf during the winter. Given the basin volume of $2.75 \times$ $10^{7} \mathrm{~m}^{2} \mathrm{~s}^{-1}$, it would take 145 days for all the water in the basin to circulate through the meltwater plume. From autumn until the return of subglacial discharge the following spring, the basin waters could all be modified (not necessarily flushed) by this mechanism.

\section{2) COMPARISOn: MODEL AND SERMILIK FJORD}

Cases $\mathrm{P}_{-} \mathrm{H}$ and $\mathrm{P} \_\mathrm{Hm}$ indicate that intermediary circulation does not renew the IIf basin because of the shallow sill. To show that this is not a vacuous result, it is important to show that our model can create a reasonable intermediary circulation in the case of a deep sill. In case P_L (Fig. 13e), the sill was still $100 \mathrm{~m}$ higher than $\mathrm{DB}$, but DB was artificially sunk to $800-\mathrm{m}$ depth so the sill was submerged in unstratified deep water. In this case, pycnocline oscillations alone (no melting) were able to induce flow in the warm, deep water (including the thin below-sill basin layer). The instantaneous flux below the thermocline and over the sill was $24 \mathrm{~m}^{2} \mathrm{~s}^{-1}$ in this snapshot. Over the 10 pycnocline cycles, the mean total influx below $300 \mathrm{~m}$ and over the sill was $2.5 \times$ $10^{6} \mathrm{~m}^{2}$ during each event, which is $24 \%$ of the volume flushed out of Sermilik Fjord during each of the 16 largest observed pulses. ${ }^{10}$ After 10 cycles (100 days) of pycnocline oscillations, the intermediary circulation in case P_L had therefore moved an area equivalent to the fjord's deep, warm layer into the fjord over the sill. As in $\mathrm{P} \_\mathrm{H}$, renewal of the deep, warm layer in $\mathrm{P}_{-} \mathrm{L}$ was less efficient than this calculation suggests (see Fig. 17 below and supplemental information).

For case P_L, we also show Hovmöller diagrams of along-fjord velocities in Fig. 15, which can be compared to similar figures in Jackson et al. (2014). They reported RMS velocities of $10-22 \mathrm{~cm} \mathrm{~s}^{-1}$ in the middle of Sermilik Fjord and $5 \mathrm{~cm} \mathrm{~s}^{-1}$ in the upper fjord, which they attribute to externally forced intermediary circulation. The

\footnotetext{
${ }^{10}$ Scaled by the $8-\mathrm{km}$ width of the fjord, the outgoing volume in our model is $2.0 \times 10^{10} \mathrm{~m}^{3}$, compared to $8.5 \times 10^{10} \mathrm{~m}^{3}$ from Jackson et al. (2014).
} 

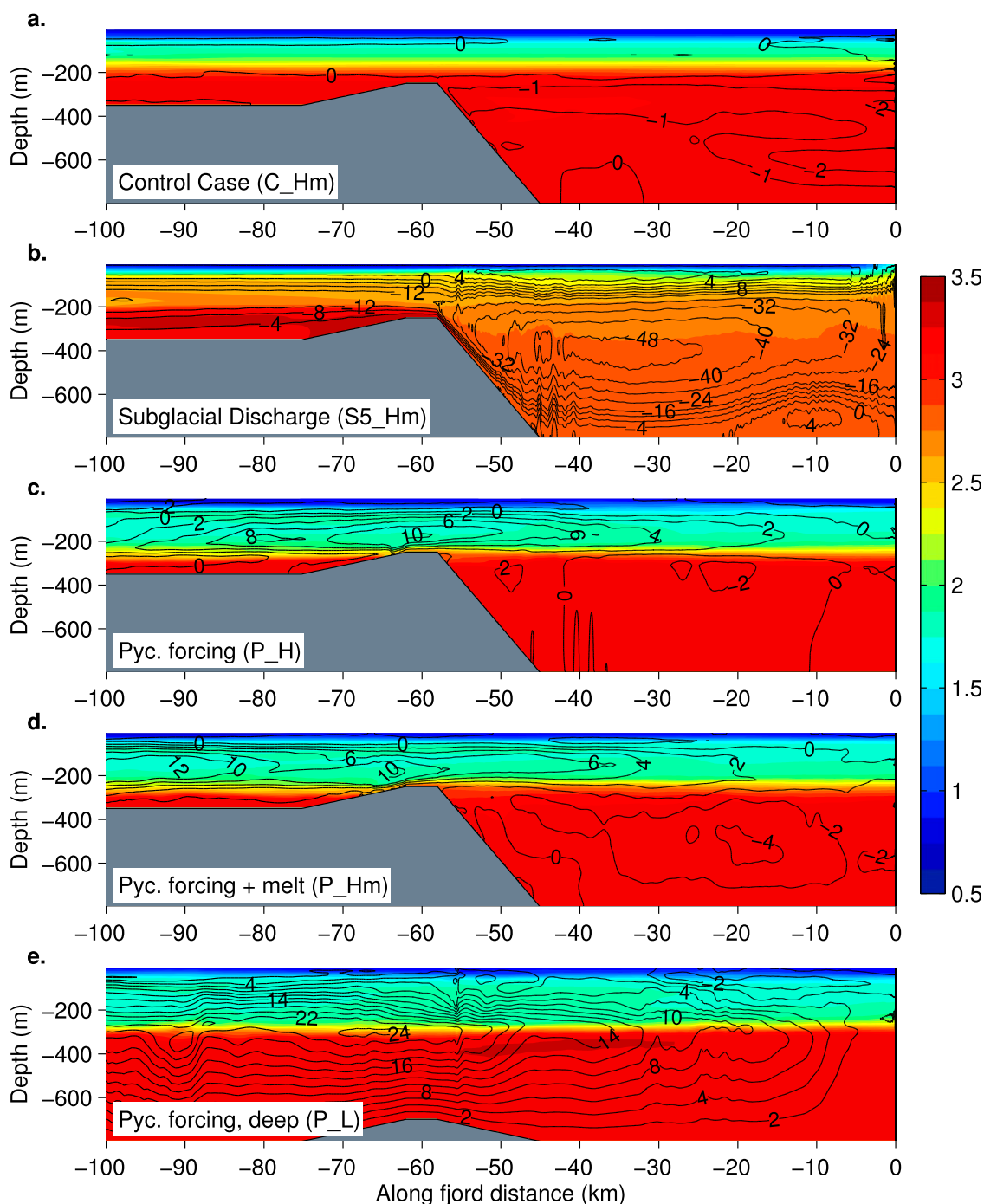

FIG. 13. Snapshots of temperature and circulation in five key model runs. Colors show potential temperature $\left({ }^{\circ} \mathrm{C}\right)$. Black lines are contours of the streamfunction $\psi\left(\mathrm{m}^{2} \mathrm{~s}^{-1}\right)$. Case definitions are shown in Table 6. (a) Case C_Hm at $t=50$ days. (b) Case S5_Hm averaged over $t=50-52$ days. The flow was mostly steady but was averaged over a 2-day period to smooth some high-frequency variability near $x=-50 \mathrm{~km}$. (c) Case $\mathrm{P} \_\mathrm{H}$ at $t=58$ days. (d) Case $\mathrm{P} \_\mathrm{Hm}$ at $t=58$ days. (e) Case P_L at $t=56$ days.

RMS speeds in our model at $100-\mathrm{m}$ depth were $7.4 \mathrm{~cm} \mathrm{~s}^{-1}$ at the fjord mouth, $6.2 \mathrm{~cm} \mathrm{~s}^{-1}$ at mid fjord, and $4.0 \mathrm{~cm} \mathrm{~s}^{-1}$ near the head of the fjord. At 300-m depth, the model RMS speeds at the same sites were 4.1,3.7, and $2.8 \mathrm{~cm} \mathrm{~s}^{-1}$, respectively. Our simulated intermediary circulation for a hypothetical deep-silled IIf is similar to that observed in Sermilik Fjord in terms of vertical structure and temporal variability and in the weakening currents toward the head of the fjord. The model's RMS speeds are smaller by a factor of 3 . The amplitude of the pycnocline oscillations we imposed in the model was arbitrary, so agreement in speeds is not to be expected, but since those oscillations were large, the lower speeds in the model probably reflect the weaker PW/AW density contrast in IIf (in summer) compared to at Sermilik Fjord (in winter).

\section{3) Comparison: Model AND IIF}

To relate our model runs to the observed XCP velocities, profiles of horizontal velocities for shallowsilled cases S5_Hm and P_H are shown in Fig. 16. In S5_Hm, subglacial discharge and glacier melting led to a fast glacierward current along the fjord basin and a compensating outflow above, as in the XCP velocity profiles (Fig. 10). The deep influxes in observed profiles V2 are V3 are both $>20 \mathrm{~m}^{2} \mathrm{~s}^{-1}$ (Table 5), which is about half of the flux along the bottom of the model fjord 


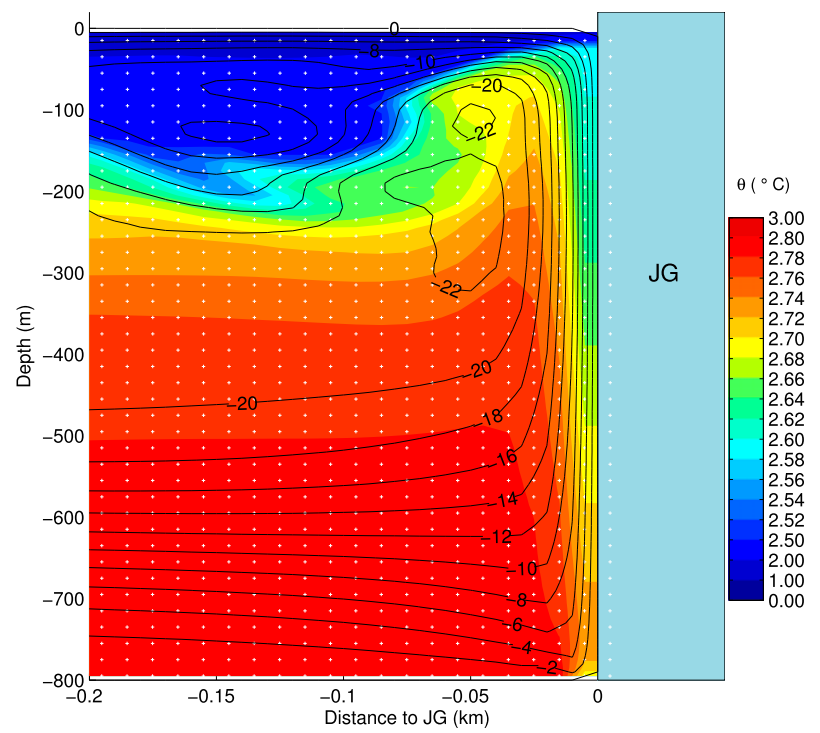

FIG. 14. Zoomed-in view of S5_Hm at $t=50$ days next to JG terminus (pale blue region on the right). Background colors are fjord temperatures (nonlinear colorscale). Black contours are of streamfunction $\psi\left(\mathrm{m}^{2} \mathrm{~s}^{-1}\right)$. White markers are the centers of model grid cells (every other one vertically).

basin. Some of this flux is an artifact of the initial adjustment of the fjord basin interior, however, and the flux of $20 \mathrm{~m}^{2} \mathrm{~s}^{-1}$ along the lower $350 \mathrm{~m}$ of the fjord basin (Fig. 14) near the glacier agrees with the observed deep basin current flux. The surface-intensified character of currents in $\mathrm{P}_{-} \mathrm{H}$ is not a good match for the observed velocity profiles.

\section{4) PASSIVE TRACER EXPERIMENTS}

We do not present the other five cases in equivalent detail, but we incorporate all runs in our analysis of the passive tracer experiments. (Animations of the passive tracer evolution for all cases are provided in the supplemental information.) We plot the time-varying fraction of each tracer remaining inside the fjord for all cases in Fig. 17. To obtain these curves, the tracer concentrations were integrated over the region to the right of the fjord sill (over all depths) at each time and divided by the integral from the initial time.

In the control case $\mathrm{C}_{-} \mathrm{Hm}, 96 \%$ of the basin tracer remained in the fjord by the end of the 100-day simulation while the above-sill tracer had dropped to $68 \%$ of its original total after 100 days. Melting alone therefore did not renew either the basin or above-sill waters of the model IIf on a subseasonal to seasonal time scale. In case S5_Hm, renewal was rapid above and below the sill depth. The half-life for the basin tracer, meaning the time required for half of the tracer to leave the fjord, was 27.5 days. This includes several days of spinup, and the slope of the tracer curve is not constant. Nevertheless, this compares reasonably well with the 32-day renewal time scale estimated from the model snapshot at day 50 and the 24-36-day renewal time scale estimated from the XCP velocities that did not take into account mixing or transient aspects of the flow. Above the sill, renewal was slightly faster, with a half-life of 20.5 days for the above-sill tracer.

Switching off melting made renewal somewhat slower (case S5_H compared to S5_Hm), with the basin tracer half-life lengthening to 31.5 days (23 days for above-sill tracer). Remarkably, when the subglacial discharge rate was doubled (case S10_Hm compared to S5_Hm), the half-life of the basin tracer lengthened to 40.5 days ( 23.5 days for above-sill waters). Lacking a complete explanation for this, we point out that in S10_Hm the plume outflow was initially at the surface, while outflow in S5_Hm was below the surface. In S10_Hm, the abovesill tracer level initially plummeted but then slowed after 10 days when the plume outflow switched to a subsurface mode and the surface waters from outside the fjord reclaimed the fjord surface. Throughout the 100-day run, there was a complex confrontation at the surface between plume outflow and the external surface waters, and this seems to have impacted the rate of exchange above and below the sill (not shown in detail, but partially clear from tracer animations).

Deepening the sill made melting alone (case C_Lm) quite effective at renewing both basin (half-life of 41 days) and above-sill waters (half-life of 56 days). Introducing subglacial discharge to the deep-silled scenario (case S5_Lm) shrank both the tracer half-lives to 14 days.

When there was a high sill, intermediary circulation was just slightly more effective than melting alone at renewing basin waters, with or without melting activated (cases $\mathrm{P}_{-} \mathrm{H}$ and $\mathrm{P} \_\mathrm{Hm}$ compared to $\mathrm{C} \_\mathrm{Hm}$ ). With a deep sill, intermediary circulation alone $\left(\mathrm{P}_{-} \mathrm{L}\right)$ did not evacuate the basin tracer effectively, but with melting activated (P_Lm) did slightly accelerate basin renewal compared to the melting-only control case (C_Lm). Intermediary circulation alone was generally ineffective at renewing basin waters compared to the renewal that would already occur because of melting at the glacier terminus.

Intermediary circulation was more effective at completely renewing waters above the sill and, especially, waters above the pycnocline. With a high sill, intermediary circulation alone $\left(\mathrm{P} \_\mathrm{H}\right)$ removed half of the above-sill tracer from the fjord after the full 100-day run. The limitations of the model probably make the abovesill renewal time scale in case $\mathrm{P} \_H$ longer than it should be since much of the tracer-laden waters leaving the fjord during one phase of the cycle reentered during the next half of the cycle. Waters just inside the fjord mouth 

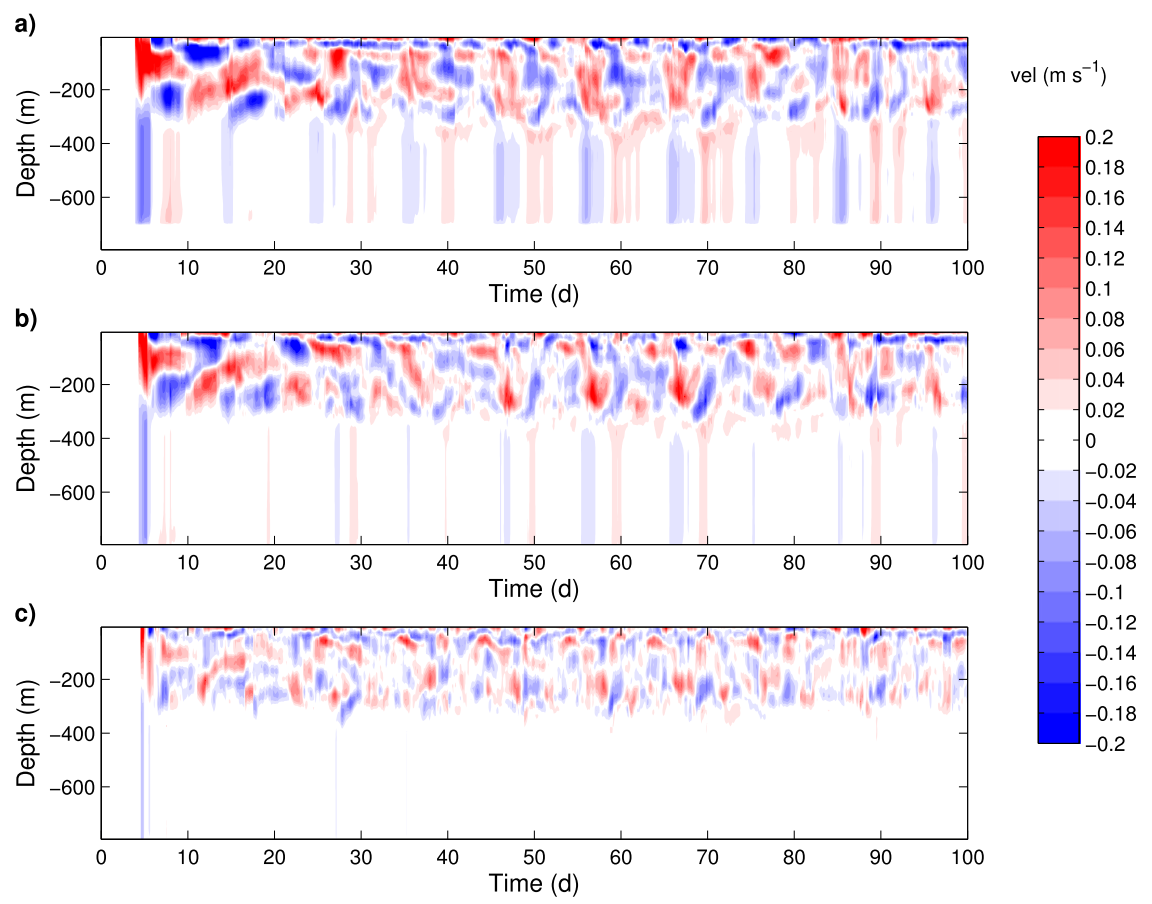

FIG. 15. Along-fjord velocities in case P_L. (a) At $60 \mathrm{~km}$ from the glacier (over the sill). (b) At $35 \mathrm{~km}$ from the glacier. (c) At $10 \mathrm{~km}$ from the glacier.

were completely renewed during the 100-day simulation, but renewal near the head of the fjord was less complete (see the supplemental information). In a three-dimensional model (and in reality), transverse currents outside the fjord might sweep away the tracer-laden water on their outward excursion and allow new water to enter the fjord on the next inflow phase, thereby rectifying the tracer outflow and accelerating the renewal rate. Activating melting in the high-silled case $\left(\mathrm{P}_{-} \mathrm{Hm}\right)$ caused little change to above-sill exchange compared to the no melting case $\left(\mathrm{P}_{-} \mathrm{H}\right)$ since the meltwater plume did not rise above the sill depth. With a low sill and no melting (P_L), $80 \%$ of the above-sill tracer remained after 100 days. The total exchange over the sill exceeded the volume of the fjord (as shown above), but the oscillatory nature of the current made the exchange inefficient.

\section{d. Validity of model plume}

The meltwater plume next to the JG terminus is the most challenging aspect of the fjord circulation to model correctly and also the most important part for the problem of renewal. If there were no mixing between subglacial discharge and ambient fjord basin water then the freshwater would simply rise to the surface and exit the fjord at the surface without driving any renewal. In our model runs with subglacial discharge, the initially freshwater was highly diluted by mixing with ambient basin water (with a ratio of 280 to 1 in case S5_Hm), so the plume outflow was composed almost entirely of basin water and renewal was very effective.

To assess the validity of the upwelling plume in our model, we compared it to the plume model in Jenkins (2011). To calculate a Jenkins-style plume, we used ambient water properties from the same summer 2009 CTD profile used in the MITgcm model and the same planar subglacial discharge rate as in case S5_Hm $\left(0.08 \mathrm{~m}^{2} \mathrm{~s}^{-1}\right)$. All turbulence parameters were those in Jenkins (2011).

The numerical solution of Jenkin's model equations yielded a plume that rose $594 \mathrm{~m}$ up the terminus wall of JG before detaching. The thickness grew nearly linearly to a maximum of $24.5 \mathrm{~m}$, and the upward velocity was $0.72-0.85 \mathrm{~m} \mathrm{~s}^{-1}$ with a mean of $0.83 \mathrm{~m} \mathrm{~s}^{-1}$. The upward flux grew nearly linearly and reached a maximum of $17.8 \mathrm{~m}^{2} \mathrm{~s}^{-1}$ at $206-\mathrm{m}$ depth. The plume temperature varied from $2.46^{\circ}$ to $2.80^{\circ} \mathrm{C}$ with a mean of $2.75^{\circ} \mathrm{C}$ after rapidly warming in the deepest $20 \mathrm{~m}$.

If we define the width of the plume in our model as the width in which the upwelling velocity is at least $25 \%$ of the maximum speed next to the wall, then the width of our plume in case S5_Hm grew gradually from $10 \mathrm{~m}$ at the base of the terminus to $30 \mathrm{~m}$ at 200-m depth. Below 200-m depth, our model's upward velocity averaged over this defined width varied from 0.41 to $0.72 \mathrm{~m} \mathrm{~s}^{-1}$, with a mean of $0.62 \mathrm{~m} \mathrm{~s}^{-1}$. At $210-\mathrm{m}$ depth, the vertical flux was $22.5 \mathrm{~m}^{2} \mathrm{~s}^{-1}$. The temperature varied from $2.69^{\circ}$ to $2.75^{\circ} \mathrm{C}$ 


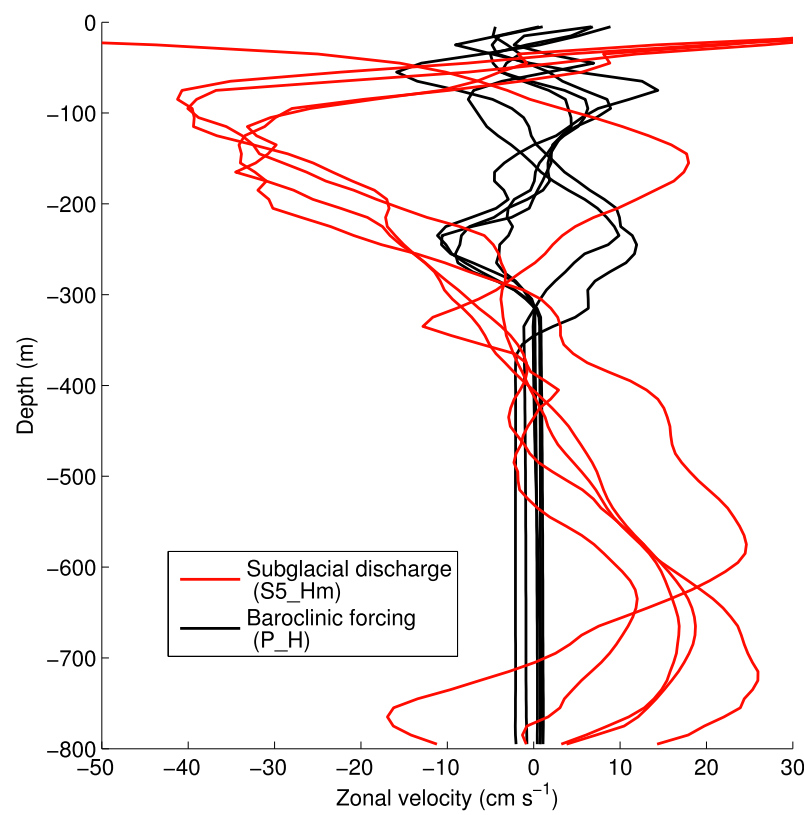

FIG. 16. Vertical profiles of model zonal velocity. Case S5_Hm reached a nearly steady state, so velocity profiles are from a fixed time (day 50) from various locations $(0.5,10,20,30$, and $40 \mathrm{~km}$ west of the glacier terminus). Case $\mathrm{P} \_\mathrm{H}$ was unsteady and the profiles shown are snapshots taken every 2 days over a 10-day period beginning on day 50 at a position $30 \mathrm{~km}$ west of the terminus.

with an average of $2.72^{\circ} \mathrm{C}$. All of these are in reasonable agreement with Jenkins' model.

If the nondimensional entrainment coefficient $E_{0}$ in Jenkins' model [Eq. (6)] is increased by $65 \%$ from $3.6 \times$ $10^{-2}$ to $5.9 \times 10^{-2}$, then Jenkins' model attains the same flux as our model at $265-\mathrm{m}$ depth and attains a width of $35 \mathrm{~m}$. The mean upwelling speed decreases to $0.71 \mathrm{~m} \mathrm{~s}^{-1}$, in better agreement with our model results. Therefore, our model reproduced a plume that entrains ambient water somewhat more readily than Jenkins' model using best-estimate parameters and hence was slower, thicker, and carried greater flux. From the XCP observations, the true glacierward flux in the deep layer at station V4 was $17 \mathrm{~m}^{2} \mathrm{~s}^{-1}$, which is in reasonable agreement with both models.

\section{Summary and conclusions}

Our summer observations, theoretical arguments, and numerical simulation results can be synthesized into the schematic picture of Ilulissat Icefjord (IIf) in summer in Fig. 18. Summer profiles show that the warmest subsurface waters in Disko Bay (DB) are blocked by the 245-m-deep sill and do not enter IIf. The intermediate depth DB waters that do enter the 750-800-m-deep fjord basin are generally in the narrow potential density range $27.20 \leq \sigma_{\theta} \leq 27.31 \mathrm{~kg} \mathrm{~m}^{-3}$. The nearly homogeneous basin waters make up most of the ambient thermal boundary condition of Jakobshavn Glacier (JG) at the head of the fjord. Near the surface there is an extremely fresh layer in the upper $100 \mathrm{~m}$ of IIf in the summer that does not extend far out into DB (a fresh surface current that flows north past the town is known to Ilulissat locals).

Warm Fjord Water (WFjW) observed in the basin in summer 2009 and 2011-13 was similar to the (inferred) basin waters of 1997/98 that triggered the retreat of JG (Holland et al. 2008; Thomas 2004; Motyka et al. 2011). In the August 2010 fjord survey, however, WFjW was completely absent and instead the fjord was filled with water more than a degree cooler. Anomalously cool water appeared in eastern Davis Strait in March 2010, and the cool anomaly seems to have arrived at the mouth of the fjord in May 2010.

Cool Fjord Water (CFjW) in 2010 was nearly the same density as WFjW from other summers $\left(27.20 \leq \sigma_{\theta} \leq\right.$ $27.31 \mathrm{~kg} \mathrm{~m}^{-3}$ ). This density class is found between the temperature minimum of cool and fresh Polar Water and the warmer layer below fed by the West Greenland Current (Fig. 4). This interface occupies various depths in DB but is often above or straddling the 200-m line (Fig. 3). Therefore, as Myers and Ribergaard (2013) suggested, the variability of waters shallower than $200 \mathrm{~m}$ (i.e., Polar Waters) in DB are a major, sometimes principle, source of variability for the thermal boundary condition of JG, despite the great depth of IIf (see also Gladish et al. 2015).

The interannual shift from WFjW (2009) to CFjW (2010) to WFjW (2011) throughout DB and IIf proved that the fjord basin was renewed at least once per year by DB waters. We therefore investigated the possible mechanisms and time scales of renewal. Velocity profiles from summer 2013 showed basin waters flowing glacierward at $5-15 \mathrm{~cm} \mathrm{~s}^{-1}$, with compensating currents flowing out of the fjord above. Paper and pencil calculations, along with MITgcm simulations, suggest the interpretation that basin waters were flowing toward the glacier where they were entrained into an upwelling plume driven by fresh subglacial discharge and melting along the terminus wall, as seen at some other marine glaciers (Motyka et al. 2003; Rignot et al. 2010; Straneo et al. 2011). The implied basin renewal time scale is approximately 1 month.

Temperature data from instrumented seal and Greenland halibut dives inside IIf show that subseasonal temperature variability was small in the basin compared to similarly dense waters at the shelf break to the west or just inside the fjord mouth along the spillway. The basin waters were dominated by interannual variability, and renewal of the fjord basin as rapid as that seen in Sermilik Fjord (Straneo et al. 2010; Jackson et al. 2014) did not likely 

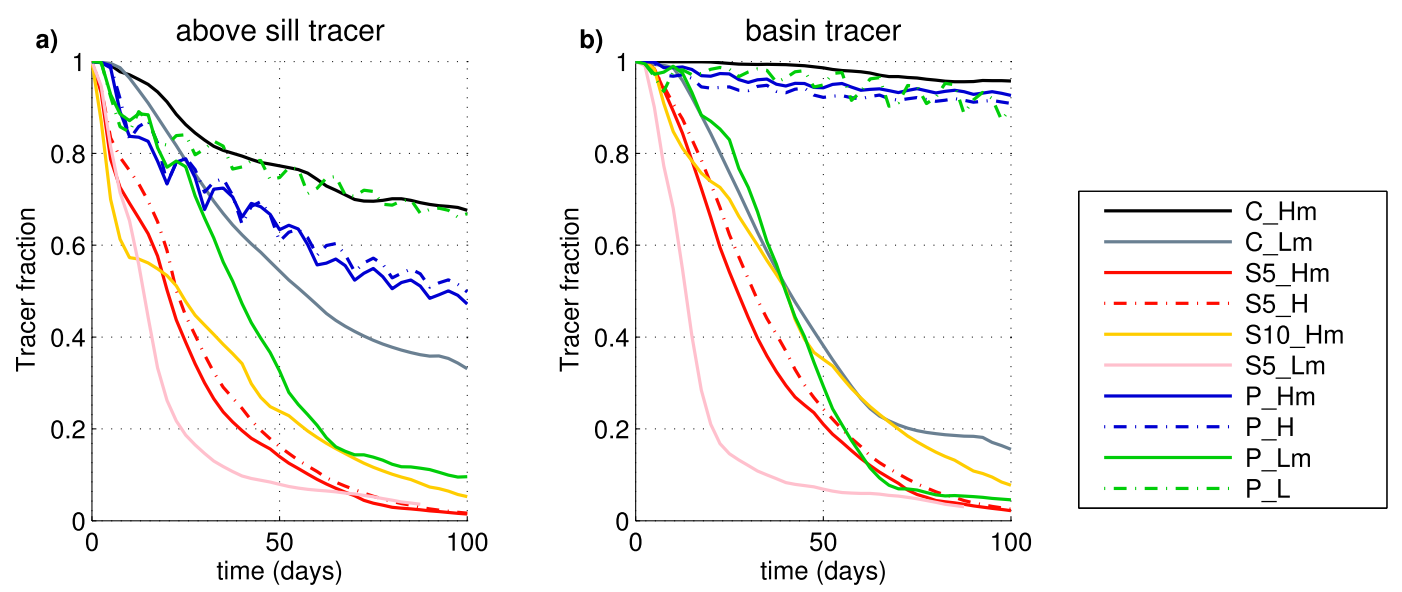

FIG. 17. Time evolution of the fraction of passive tracers remaining in the fjord in all model runs from Table 6 .

occur outside of summer. Our model results show that external baroclinic forcing, which drives subseasonal variability and renewal at Sermilik Fjord, is prevented from driving renewal of the IIf basin by the shallow sill.

Variability associated with the seasonal cycle in the IIf basin was also small, as was variability in eastern DB at 350-m depth. Here, small means small compared to the $3^{\circ} \mathrm{C}$ annual range of temperatures observed at $200-\mathrm{m}$ depth in DB (Hansen et al. 2012) or to the even larger annual range of temperatures in West Greenland Current waters on fixed isopycnals (Curry et al. 2014; Gladish et al. 2015). From autumn to midwinter, fjord isopycnals gradually descended (the basin became slightly cooler and fresher), and at the same time the fresh summer surface layer disappeared. The gradual basin cooling may have been produced by the shutdown of exchange with DB and the cycling of basin waters through a winter terminus plume (driven only by melting) that was not buoyant enough to escape the fjord basin. From January until late spring the fjord isopycnals gradually rose, possibly in response to isopycnals outside the fjord rising in the course of the regional seasonal cycle (Gladish et al. 2015).

Below the sill depth, any large temperature changes in IIf probably occur after the onset of superficial melting over the drainage basin of JG. Once this water crosses the grounding line, the extra buoyancy provided to the terminus plume allows it to rise above the sill depth and makes it energetic enough to entrain the massive amounts of basin water required to renew the basin. As new water replaces the old, potentially new water properties come into contact with the glacier.

If the residence time of basin waters in summer is 30 days and the thermal forcing for inflowing waters is $5^{\circ} \mathrm{C}$, the heat available for melting that enters the fjord each month is $40 \times 10^{17} \mathrm{~J}$. The heat removed by melting at $\mathrm{JG}$ terminus in that time, assuming a rate of $4 \mathrm{~m} \mathrm{day}^{-1}$, is
$1.5 \times 10^{17} \mathrm{~J}$. Only $4 \%$ of the heat entering the fjord is consumed by melting. Besides the fact that the sill blocks the very warmest DB waters from entering the IIf basin, the fjord circulation therefore does not significantly restrict the rate at which heat is brought near the glacier in summer. It is the turbulent dynamics of the boundary plume that throttles the rate of heat transfer toward the ice, not the total heat content of DB/IIf.

The CFjW in the IIf basin in 2010 was nearly as cold as the (inferred) basin waters of the 1980s, before the massive retreat of JG. The effect of temporarily reversing the sudden warming of 1997/98 appears to have been small, however, with glacier velocities from summer 2010 to spring 2011 (when CFjW was likely in the basin) bearing little sign of changed oceanic influence (Joughin et al. 2014). A key question for the future of JG is the following: Is calving at the vertical terminus controlled by melting (O'Leary and Christoffersen 2013) or by purely internal glacier dynamics [certain mechanisms in Benn et al. (2007)]? After all, if calving were somehow to stop, the glacier would advance to fill the entire fjord in just a few years and would surely thicken and slow (Joughin et al. 2008). The role ocean temperatures play in the delicate near balance between calving velocity and ice velocity must be understood before it will be possible to predict the future response of JG to ocean temperature variability.

Acknowledgments. NYU observations at Ilulissat were supported by NSF Office of Polar Program Grants ARC-0806393 and ARC-1304137, NASA Polar Programs Grant NNX08AN52G, and the NYU Abu Dhabi Center for Global Sea Level Change Grant G1204. Several CTD profiles collected in 2007 were contributed by Søren Rysgaard. CTD data at the fjord mouth were collected by Ian Howat in summer 2008. CTD data for 2011 in DB were collected by the GINR. CTD data in 


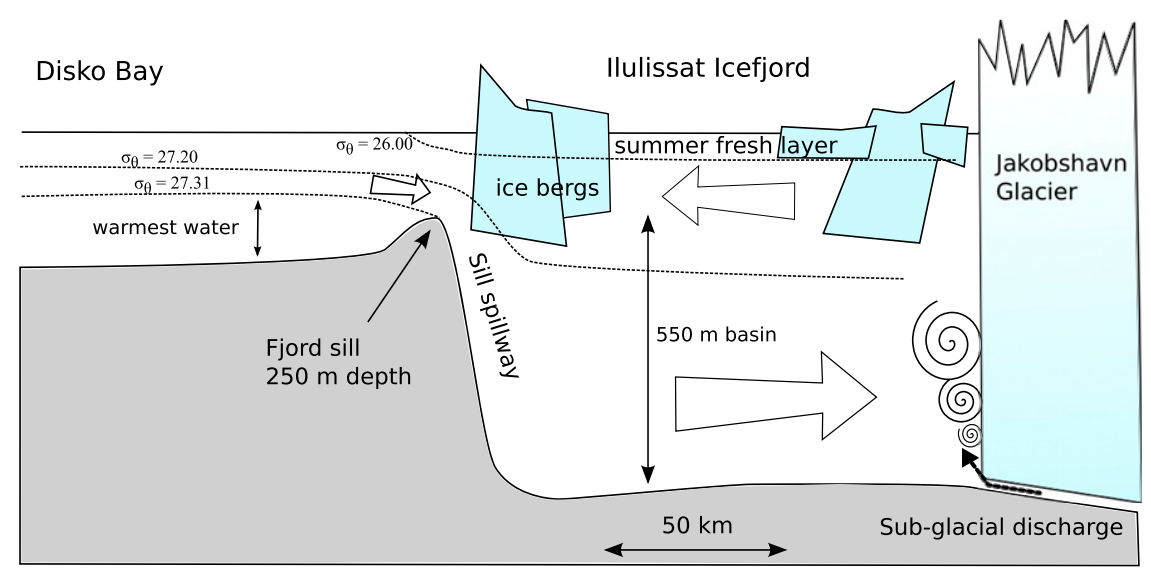

FIG. 18. Schematic diagram of IIf based on our findings.

DB collected by DMI (led by Mads Ribergaard in recent years) on behalf of the GINR were downloaded from the ICES Oceanographic database. Marc Hansen and Torkel Nielsen (Tech University of Denmark) made the Arctic Station CTD dataset available to us for this work. XCP velocity data in the fjord during 2013 were collected by Denise Holland. Mitch Bushuk assisted with the NYU CTD survey in summer 2012. Ole Eigaard processed the instrumented halibut data. MITgcm computations were carried out using NYU High Performance Computing clusters in New York and Abu Dhabi. One-dimensional plume solutions were computed using code written by Adrian Jenkins. Comments from two anonymous reviewers led to major improvements.

\section{APPENDIX A}

\section{Tides in IIf}

The gravest barotropic fjord seiche mode has a pe$\operatorname{riod}$ of $4 L / \sqrt{g H}=45 \mathrm{~min}$, with a fjord depth $H=800 \mathrm{~m}$ and length $L=60 \mathrm{~km}$. MacAyeal et al. (2012) show that this period may be lengthened to a few hours when deep-drafted icebergs are present throughout the fjord. Nevertheless, this seiche mode is too high frequency to resonate with the semidiurnal barotropic tide. The sea surface throughout the fjord therefore rises and falls uniformly and barotropic tidal currents in the fjord at a given location are no larger than $v=A R \pi /(C T)$, where $A$ is the surface area of the fjord landward of the given location, $R=2.75 \mathrm{~m}$ is the maximum tidal range (from the pressure record for Fjord $400 \mathrm{~m}$ ), $C$ is the vertical cross-sectional area of the fjord at the given location, and $T=12 \mathrm{~h}$ is the semidiurnal period. For stations V2, V3, and $\mathrm{V} 4$, which are inland of the areally large north and south arms of the fjord, we take $A=D W$ and $C=W H$, where $D$ is the distance to the ice front, $W$ is the width of the fjord, and $H$ is the depth. Then $v=D R \pi /(H T)$, with tidal velocities decreasing to zero toward the ice front. At V2, we estimate $v=0.0075 \mathrm{~m} \mathrm{~s}^{-1}$ and at V3 and V4, $v$ is even smaller. At the three landward stations, barotropic tidal velocities are insignificant compared to the signals in the XCP profiles. At V1, making the crude approximation that the north and south arms together double the area of the fjord (compared to the main eastwest channel alone), we estimate $v=0.03 \mathrm{~m} \mathrm{~s}^{-1}$. This is not negligible, but it is still smaller than the $0.15 \mathrm{~m} \mathrm{~s}^{-1}$ current flowing toward the glacier in the bottom $100 \mathrm{~m}$ or the $0.07 \mathrm{~m} \mathrm{~s}^{-1}$ current flowing out of the fjord over the sill (Fig. 10a).

Internal tides generated at the fjord mouth also do not dominate the XCP velocity profiles. To estimate the size of internal tidal velocities in the fjord basin, we conceptually model the fjord as a two-layer system (Fig. A1).

In the fjord interior $(x>0)$, the governing equations, linearized about a state of rest, are

$$
\begin{aligned}
& \frac{\partial u_{1}}{\partial t}=-g \frac{\partial \eta}{\partial x} \\
& \frac{\partial \eta}{\partial t}=-H_{1} \frac{\partial u_{1}}{\partial x}, \\
& \frac{\partial u_{2}}{\partial t}=-g \frac{\rho_{1}}{\rho_{2}} \frac{\partial \eta}{\partial x}-g^{\prime} \frac{\partial \eta^{\prime}}{\partial x}, \quad \text { and } \\
& \frac{\partial \eta^{\prime}}{\partial t}=-H_{2} \frac{\partial u_{2}}{\partial x},
\end{aligned}
$$

where $g^{\prime}=g\left(\rho_{2}-\rho_{1}\right) / \rho_{2}$ is the reduced gravity. We let $u_{b}$ denote the barotropic tide, which applies to both layers, and we suppose that $u_{1}$ and $u_{2}$ constitute a baroclinic mode solution. Baroclinic mode waves have phase speed 


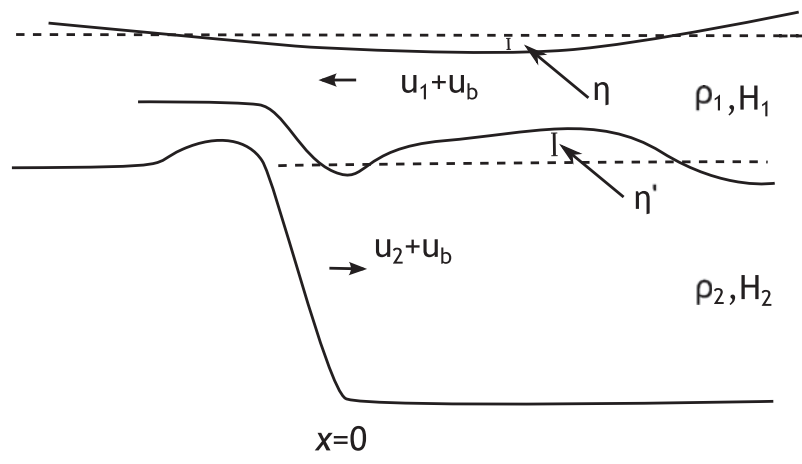

FIG. A1. Two-layer conceptual model to estimate internal tidal velocities.

$c=\sqrt{\left(g^{\prime} H_{1} H_{2}\right) /\left(H_{1}+H_{2}\right)}$. Using $\rho_{1}=1026 \mathrm{~kg} \mathrm{~m}^{-3}$ (typical at $100-\mathrm{m}$ depth), $\rho_{2}=1027.3 \mathrm{~kg} \mathrm{~m}^{-3}$ (typical of fjord basin), $H_{1}=300 \mathrm{~m}$, and $H_{2}=500 \mathrm{~m}$, we obtain $c=$ $1.0 \mathrm{~m} \mathrm{~s}^{-1}$. This is faster than the barotropic tide $u_{b 0}=$ $0.03 \mathrm{~m} \mathrm{~s}^{-1}$, assumed equal to the above estimate for station V1. In the terminology of Stigebrandt and Aure (1989), IIf therefore has a wave basin, and it is expected that the internal tide propagates into the basin (rather than being dissipated near the sill).

To the right of the spillway, we suppose therefore that the interface deviation $\eta^{\prime}$ and the baroclinic velocities have the form of traveling waves

$$
\begin{aligned}
& u_{1}=\hat{u}_{1} e^{i(k x-\omega t)} \\
& u_{2}=\hat{u}_{2} e^{i(k x-\omega t)} \\
& \eta^{\prime}=\hat{\eta} e^{i(k x-\omega t)},
\end{aligned}
$$

where $\omega=k c$ is the semidiurnal tidal frequency. As the barotropic tide flows in and out of the fjord, water columns over the spillway are stretched or compressed. Just to the left of the foot of the spillway (at $x=0$ ), the vertical velocity of the interface because of this stretching is

$$
\frac{\partial \eta^{\prime}}{\partial t}=m\left(u_{b}+u_{2}\right) \frac{H_{1}}{H_{1}+H_{2}}-\left(u_{b}+u_{2}\right) \frac{\partial \eta^{\prime}}{\partial x},
$$

where $m$ is the slope of the spillway. Assuming the spillway drops $500 \mathrm{~m}$ over $5 \mathrm{~km}, m=-0.1$. We will neglect the last term in (A5), noting that the mean slope of $\eta^{\prime}$ is not necessarily small (compared to $m$ ) over the spillway, but since it is negative, it opposes the effect of the spillway slope $m$ and therefore tends to decrease the amplitude of $\partial \eta^{\prime} / \partial t$.

Taking $u_{b}=u_{b 0} e^{-i \omega}$ and matching (A4) and (A5) at $x=0$, we obtain

$$
\hat{u}_{2}=\left(\frac{-m}{i\left(H_{1}+H_{2}\right) \frac{H 2}{H 1} \frac{\omega}{c}+m}\right) u_{b 0} .
$$

When the spillway is vertical $(m \rightarrow-\infty)$, this model reduces to that of Stigebrandt (2012) in which $u_{2}=-u_{b}$. Using parameters for IIf,

$$
\hat{u}_{2}=\frac{-0.1}{0.2 i+0.1} u_{b 0}=0.5 e^{i \times 2.1} u_{b 0} .
$$

The baroclinic basin layer velocity is therefore half the amplitude of the barotropic tidal velocity $\left(\left|\hat{u}_{2}\right|=0.015 \mathrm{~m} \mathrm{~s}^{-1}\right)$, and it is out of phase by one-third of a cycle. The amplitude of the interface oscillation are $|\hat{\eta}|=H_{2}\left|\hat{u}_{2}\right| / c=7.5 \mathrm{~m}$.

This estimate implies that the internal tide propagating into the fjord basin generates velocity signals at the level of noise in the XCP velocity profiles. There are two potential objections to this reasoning, to which we briefly respond. First, the geometry of the sill and spillway is complicated, and it is possible that the true interface motions are larger than in our estimate. However, the quasi-permanent slope in the $\eta^{\prime}$ interface (seen in all summer XCTD surveys) means that the vertical deviations of the interface due to the barotropic tide are smaller than they would be if the mean interface were flat, as we assumed. Second, if the internal waves propagate to the end of the fjord and reflect back to the mouth without losing too much energy, internal seiche modes of an arbitrarily large amplitude could be set up (since $\eta^{\prime}$ would have a node at $x=0$ in that case). Such an internal seiche oscillation would not, however, account for the XCP velocity profiles. The gravest (along fjord) internal seiche mode has period $T_{0}=4 L / c=2.8 \mathrm{~d}$, which is 5 times longer than the semidiurnal period. Only the gravest seiche mode would generate bottom layer velocities that were all in the same direction in a synoptic survey (comprising V1, V2, and V3, but not V4).

\section{APPENDIX B}

\section{Intermediary Circulation in Klinck et al. (1981)}

We find that the model equations of Klinck et al. (1981) are incorrectly linearized for sills occupying a large fraction of the deep layer. First of all, for their Eqs. (1)-(6) to be reasonable, their layer variables $h_{1}$ and $h_{2}$ must be interpreted as the deviations of the layer thicknesses from background constants $H_{1}$ and $H_{2}$, not as deviations of the upper and interface surface heights from the mean horizontal positions as implied in their Fig. 2. Then the lowerlayer thickness is exactly $\mathrm{H}_{2}+h_{2}$. In their lower-layer momentum Eq. (4), $H_{2}+h_{2}$ is approximated by $H_{2}$, assuming that $h_{2}$ is small. In this notation, the correct variation of the interface from horizontal is $D(x)+h_{2}$, where $D(x)$ is the bottom topography. Assuming the topographic variations are much larger than the interface 
variations (over a tall sill, in this case), $h_{2} \approx-D(x)$, so a better approximation of $H_{2}+h_{2}$ is $H_{2}-D(x)$. Replacing $\mathrm{H}_{2}$ by $\mathrm{H}_{2}-D(x)$ in their Eq. (4) produces a linear (though no longer constant coefficient) equation that should be more suitable for the case of a very tall sill. This would decrease momentum fluxes over the sill into the lower layer when there is a very tall sill [when $\mathrm{H}_{2}-D(x)$ becomes small], making the basin more quiescent. For example, with this correction, transport into or out of the basin vanishes when the sill height $D(x)$ equals the lowerlayer thickness $H_{2}$.

\section{REFERENCES}

Amundson, J., M. Fahnestock, M. Truffer, J. Brown, M. Lüthi, and R. Motyka, 2010: Ice mélange dynamics and implications for terminus stability, Jakobshavn Isbræ, Greenland. J. Geophys. Res., 115, F01005, doi:10.1029/2009JF001405.

Andersen, O., 1981: The annual cycle of temperature, salinity, currents and water masses in Disko Bugt and adjacent waters, west Greenland. Medd. Groenl. Biosci., 5, 3-33.

Arneborg, L., 2004: Turnover times for the water above sill level in Gullmar Fjord. Cont. Shelf Res., 24, 443-460, doi:10.1016/ j.csr.2003.12.005.

— C. Erlandsson, B. Liljebladh, and A. Stigebrandt, 2004: The rate of inflow and mixing during deep-water renewal in a sill fjord. Limnol. Oceanogr., 49, 768-777, doi:10.4319/lo.2004.49.3.0768.

Benn, D., C. Warren, and R. Mottram, 2007: Calving processes and the dynamics of calving glaciers. Earth-Sci. Rev., 82, 143-179, doi:10.1016/j.earscirev.2007.02.002.

Boje, J., S. Neuenfeldt, C. Sparrevohn, O. Eigaard, and J. Behrens, 2014: Seasonal migration, vertical activity and winter temperature experience of Greenland halibut Reinhardtius hippoglossoides (Walbaum) in west Greenland waters. Mar. Ecol. Prog. Ser., 508, 211-222, doi:10.3354/meps10874.

Christoffersen, P., R. Mugford, K. Heywood, I. Joughin, J. Dowdeswell, J. Syvitski, A. Luckman, and T. Benham, 2011: Warming of waters in an east Greenland fjord prior to glacial retreat: Mechanisms and connection to large-scale atmospheric conditions. Cryosphere, 5, 701-714, doi:10.5194/tc-5-701-2011.

Colville, E., A. Carlson, B. Beard, R. Hatfield, J. Stoner, A. Reyes, and D. Ullman, 2011: Sr-Nd-Pb isotope evidence for ice-sheet presence on southern Greenland during the last interglacial. Science, 333, 620-623, doi:10.1126/science.1204673.

Curry, B., C. Lee, B. Petrie, R. Moritz, and R. Kwok, 2014: Multiyear volume, liquid freshwater, and sea ice transports through Davis Strait, 2004-10. J. Phys. Oceanogr., 44, 1244-1266, doi:10.1175/JPO-D-13-0177.1.

Cushman-Roisin, B., L. Asplin, and H. Svendsen, 1994: Upwelling in broad fjord. Cont. Shelf Res., 14, 1701-1721, doi:10.1016/ 0278-4343(94)90044-2.

Dahl-Jensen, D., and Coauthors, 2013: Eemian interglacial reconstructed from a Greenland folded ice core. Nature, 493, 489-494, doi:10.1038/nature11789.

Echelmeyer, K., and W. Harrison, 1990: Jakobshavn Isbræ, west Greenland: Seasonal variations in velocity—or lack thereof. J. Glaciol., 36, 82-88.

Gade, H., and A. Edwards, 1980: Deep water renewal in fjords. Fjord Oceanography, NATO Conference Series, Vol. 4, Plenum Press, 453-488.
Gladish, C., D. Holland, and C. Lee, 2015: Oceanic boundary conditions for Jakobshavn Glacier. Part II: Provenance and sources of variability of Disko Bay and Ilulissat Icefjord waters, 1990-2011. J. Phys. Oceanogr., 45, 33-63, doi:10.1175/ JPO-D-14-0045.1.

Hammer, R., 1883: Undersøgelser ved Jakobshavns isfjord og nærmeste omegn i vinteren 1879-1880. Medd. Groenl., 4, 1-68.

Hansen, M., T. Nielsen, C. Stedmon, and P. Munk, 2012: Oceanographic regime shift during 1997 in Disko Bay, western Greenland. Limnol. Oceanogr., 57, 634-644, doi:10.4319/ lo.2012.57.2.0634.

Holland, D., R. Thomas, B. D. Young, M. Ribergaard, and B. Lyberth, 2008: Acceleration of Jakobshavn Isbræ triggered by warm subsurface ocean waters. Nat. Geosci., 1, 659-664, doi:10.1038/ngeo316.

Howat, I., I. Joughin, and T. Scambos, 2007: Rapid changes in ice discharge from Greenland outlet glaciers. Science, 315, 15591561, doi:10.1126/science.1138478.

- , Y. Ahn, I. Joughin, M. van den Broeke, J. Lenaerts, and B. Smith, 2011: Mass balance of Greenland's three largest outlet glaciers, 2000-2010. Geophys. Res. Lett., 38, L12501, doi:10.1029/2011GL047565.

Inall, M., and P. Gillibrand, 2010: The physics of mid-latitude fjords: A review. Geol. Soc. London Spec. Publ., 344, 17-33, doi:10.1144/SP344.3.

IOC, SCOR, and IAPSO, 2010: The International Thermodynamic Equation of Seawater-2010: Calculation and use of thermodynamic properties. Intergovernmental Oceanographic Commission, Manuals and Guides 56, 220 pp. [Available online at http://www.teos-10.org/pubs/TEOS-10_Manual.pdf.]

Jackson, R., F. Straneo, and D. Sutherland, 2014: Externally forced fluctuations in ocean temperature at Greenland glaciers in non-summer months. Nat. Geosci., 7, doi:10.1038/ngeo2186.

Jakobsson, M., and Coauthors, 2012: The International Bathymetric Chart of the Arctic Ocean (IBCAO) version 3. Geophys. Res. Lett., 39, L12609, doi:10.1029/2012GL052219.

Jenkins, A., 2011: Convection-driven melting near the grounding lines of ice shelves and tidewater glaciers. J. Phys. Oceangr., 41, 2279-2294, doi:10.1175/JPO-D-11-03.1.

Johnson, H., A. Münchow, K. Falkner, and H. Melling, 2011: Ocean circulation and properties in Petermann Fjord, Greenland. J. Geophys. Res., 116, C01003, doi:10.1029/ 2010JC006519.

Joughin, I., I. Howat, M. Fahnestock, B. Smith, W. Krabill, R. Alley, H. Stern, and M. Truffer, 2008: Continued evolution of Jakobshavn Isbræ following its rapid speedup. J. Geophys. Res., 113, F04006, doi:10.1029/2008JF001023.

, R. Alley, and D. Holland, 2012a: Ice-sheet response to oceanic forcing. Science, 338, 1172-1176, doi:10.1126/science.1226481.

- B. Smith, I. Howat, D. Floricioiu, R. Alley, M. Truffer, and M. Fahnestock, 2012b: Seasonal to decadal scale variations in the surface velocity of Jakobshavn Isbræ, Greenland: Observations and model-based analysis. J. Geophys. Res., 117, F02030, doi:10.1029/2011JF002110.

, — - D. Shean, and D. Floricioiu, 2014: Brief communication: Further summer speedup of Jakobshavn Isbræ. Cryosphere, 8, 209-214, doi:10.5194/tc-8-209-2014.

Klinck, J., J. O'Brien, and H. Svendsen, 1981: A simple model of fjord and coastal circulation interaction. J. Phys. Oceanogr., 11, 1612-1626, doi:10.1175/1520-0485(1981)011<1612: ASMOFA $>2.0 . \mathrm{CO} ; 2$.

Large, W., J. McWilliams, and S. Doney, 1994: Oceanic vertical mixing: A review and a model with a nonlocal boundary layer 
parameterization. Rev. Geophys., 32, 363-403, doi:10.1029/ 94RG01872.

Levermann, A., P. Clark, B. Marzeion, G. Milne, D. Pollard, V. Radic, and A. Robinson, 2013: The multimillennial sealevel commitment of global warming. Proc. Natl. Acad. Sci. USA, 110, 13 745-13 750, doi:10.1073/pnas.1219414110.

Lloyd, J., M. Moros, K. Perner, R. Telford, A. Kuijpers, E. Jansen, and D. McCarthy, 2011: A $100 \mathrm{yr}$ record of ocean temperature control on the stability of Jakobshavn Isbræ, west Greenland. Geology, 39, 867-870, doi:10.1130/G32076.1.

Luckman, A., and T. Murray, 2005: Seasonal variation in velocity before retreat of Jakobshavn Isbræ, Greenland. Geophys. Res. Lett., 32, L08501, doi:10.1029/2005GL022519.

MacAyeal, D., J. Freed-Brown, W. Zhang, and J. Amundson, 2012: The influence of ice melange on fjord seiches. Ann. Glaciol., 53 (60), 45-49, doi:10.3189/2012/AoG60A027.

Marshall, J., C. Hill, L. Perelman, and A. Adcroft, 1997: Hydrostatic, quasi-hydrostatic, and nonhydrostatic ocean modeling. J. Geophys. Res., 102, 5733-5752, doi:10.1029/96JC02776.

McDougall, T., and P. Barker, 2011: Getting started with TEOS-10 and the Gibbs Seawater (GSW) oceanographic toolbox, version3.0. SCOR/IAPSO WG127, 28 pp. [Available online at http://www.teos-10.org/pubs/Getting_Started.pdf.]

Mernild, S., G. Liston, K. Steffen, and P. Chylek, 2010: Meltwater flux and runoff modeling in the ablation area of Jakobshavn Isbræ, west Greenland. J. Glaciol., 56, 20-32, doi:10.3189/ 002214310791190794

Mortensen, J., K. Lennert, J. Bendtsen, and S. Rysgaard, 2011: Heat sources for glacial melt in a sub-Arctic fjord (Godthåbsfjord) in contact with the Greenland Ice Sheet. J. Geophys. Res., 116, C01013, doi:10.1029/2010JC006528.

Motyka, R., L. Hunter, K. Echelmeyer, and C. Conner, 2003: Submarine melting at the terminus of a temperate tidewater glacier, LeConte Glacier, Alaska, USA. Ann. Glaciol., 36, 57 65, doi:10.3189/172756403781816374.

_ M. Truffer, M. Fahnestock, J. Mortensen, S. Rysgaard, and I. Howat, 2011: Submarine melting of the 1985 Jakobshavn Isbræ floating tongue and the triggering of the current retreat. J. Geophys. Res., 116, F01007, doi:10.1029/2009JF001632.

Murray, T., and Coauthors, 2010: Ocean regulation hypothesis for glacier dynamics in southeast Greenland and implications for ice sheet mass changes. J. Geophys. Res., 115, F03026, doi:10.1029/2009JF001522.

Myers, P., and M. Ribergaard, 2013: Warming of the polar water layer in Disko Bay and potential impact on Jakobshavn Isbræ. J. Phys. Oceanogr., 43, 2629-2640, doi:10.1175/JPO-D-12-051.1.

O'Leary, M., and P. Christoffersen, 2013: Calving on tidewater glaciers amplified by submarine frontal melting. Cryosphere, 7, 119-128, doi:10.5194/tc-7-119-2013.

Orlanski, I., 1976: A simple boundary condition for unbounded hyperbolic flows. J. Comput. Phys., 21, 251-269, doi:10.1016/ 0021-9991(76)90023-1.

Pritchard, H., R. Arthern, D. Vaughan, and L. Edwards, 2009: Extensive dynamic thinning on the margins of the Greenland and Antarctic Ice Sheets. Nat. Geosci., 461, 971-975, doi:10.1038/nature08471.

Ribergaard, M., 2013: Oceanographic investigations off west Greenland 2012. NAFO Scientific Council Documents Tech. Rep. 13/003, 50 pp. [Available online at http://ocean.dmi.dk/ staff/mhri/Docs/scr13-003.pdf.]
Rignot, E., and P. Kanagaratnam, 2006: Changes in the velocity structure of the Greenland Ice Sheet. Science, 311, 986-990, doi:10.1126/science.1121381.

— , and K. Steffen, 2008: Channelized bottom melting and stability of floating ice shelves. Geophys. Res. Lett., 35, L02503, doi:10.1029/2007GL031765.

- M. Koppes, and I. Velicogna, 2010: Rapid marine melting of the calving faces of west Greenland glaciers. Nat. Geosci., 3, 187-191, doi:10.1038/ngeo765.

—, I. Fenty, D. Menemenlis, and Y. Xu, 2012: Spreading of warm ocean waters around Greenland as a possible cause for glacier acceleration. Ann. Glaciol., 53 (60), 257-266, doi:10.3189/ 2012AoG60A136.

Schumann, K., D. Völker, and W. Weinrebe, 2012: Acoustic mapping of the Ilulissat Ice Fjord mouth, west Greenland. Quat. Sci. Rev., 40, 78-88, doi:10.1016/j.quascirev.2012.02.016.

Sciascia, R., F. Straneo, C. Cenedese, and P. Heimbach, 2013: Seasonal variability of submarine melt rate and circulation in an east Greenland fjord. J. Geophys. Res. Oceans, 118, 2492 2506, doi:10.1002/jgrc.20142.

Shepherd, A., and Coauthors, 2012: A reconciled estimate of icesheet mass balance. Science, 338, 1183-1189, doi:10.1126/ science. 1228102 .

Stigebrandt, A., 2012: Hydrodynamics and circulation of fjords. Encyclopedia of Lakes and Reservoirs, Encyclopedia of Earth Sciences Series, Springer, 327-344, doi:10.1007/ 978-1-4020-4410-6_247.

— , and J. Aure, 1989: Vertical mixing in basin waters of fjords. J. Phys. Oceanogr., 19, 917-926, doi:10.1175/1520-0485(1989)019<0917: $\mathrm{VMIBWO}>2.0 . \mathrm{CO} ; 2$.

Straneo, F., G. Hamilton, D. Sutherland, L. Stearns, F. Davidson, M. Hammill, G. Stenson, and A. Rosing-Asvid, 2010: Rapid circulation of warm subtropical waters in a major glacial fjord in east Greenland. Nat. Geosci., 3, 182-186, doi:10.1038/ngeo764.

_ R. Curry, D. Sutherland, G. Hamilton, C. Cenedese, K. Våge, and L. Stearns, 2011: Impact of fjord dynamics and glacial runoff on the circulation near Helheim Glacier. Nat. Geosci., 4, 322-327, doi:10.1038/ngeo1109.

_ and Coauthors, 2012: Characteristics of ocean waters reaching Greenland's glaciers. Ann. Glaciol., 53 (60), 202-210, doi:10.3189/2012AoG60A059.

Thomas, R., 2004: Force-perturbation analysis of recent thinning and acceleration of Jakobshavn Isbræ, Greenland. J. Glaciol., 50 (168), 57-66, doi:10.3189/172756504781830321.

—, E. Frederick, W. Krabill, S. Manizade, and C. Martin, 2009: Recent changes on Greenland outlet glaciers. J. Glaciol., 55 (189), 147-162.

Whitehead, J., 1998: Topographic control of oceanic flows in deep passages and straits. Rev. Geophys., 36, 423-440, doi:10.1029/ 98RG01014.

Xu, Y., E. Rignot, D. Menemenlis, and M. Koppes, 2012: Numerical experiments on subaqueous melting of Greenland tidewater glaciers in response to ocean warming and enhanced subglacial runoff. Ann. Glaciol., 53 (60), 229-234, doi:10.3189/ 2012AoG60A139.

, - - I. Fenty, D. Menemenlis, and M. Flexas, 2013: Subaqueous melting of Store Glacier, west Greenland from threedimensional, high-resolution numerical modeling and ocean observations. Geophys. Res. Lett., 40, 4648-4653, doi:10.1002/ grl.50825. 